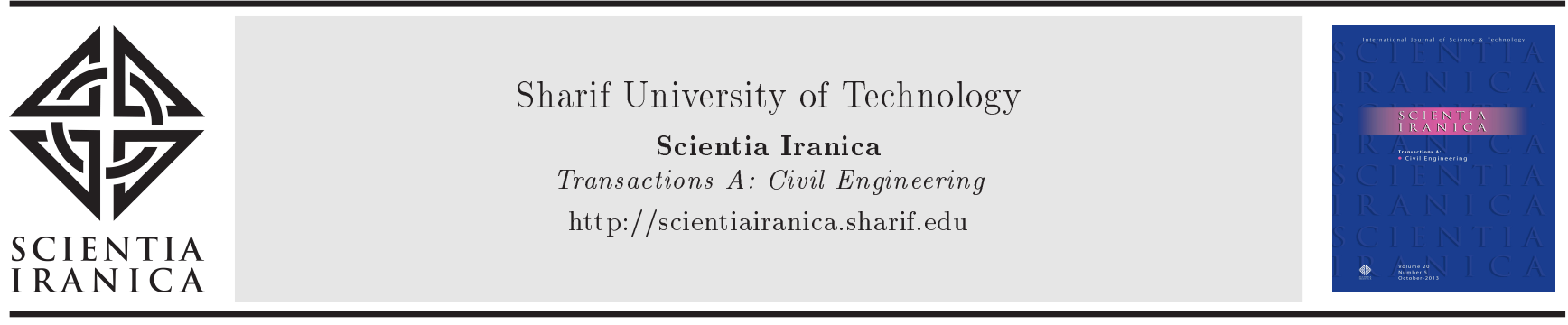

\title{
Effects of seismic pounding between adjacent structures considering structure-soil-structure interaction
}

\author{
M. Kermani, M.M. Saadatpour, F. Behnamfar*, and M. Ghandil \\ Department of Civil Engineering, Isfahan University of Technology, Isfahan, P.O. Box 8415683111, Iran.
}

Received 19 October 2017; received in revised form 4 July 2018; accepted 6 May 2019

\section{KEYWORDS}

Structure-soil-

structure interaction;

Tall building;

Pounding;

Ground motion;

Ductility demand.

\begin{abstract}
Structures located beside each other interact under dynamic loads through the underlying soil and possibly by impact. In this paper, this dynamic cross-interaction phenomenon is studied parametrically. While simultaneous modeling of different adjacent buildings would be possible from the beginning, by resorting to simple physical models, the cases susceptible to impact under harmonic loads were identified first with much less effort. Then, comprehensive models were developed with two nonlinear multistory shear buildings connected at the base with suitable springs and dampers, impacting at the story level. The system was analyzed under selected ground motions. It was observed that impact and cross-interaction had an increasing effect on lateral displacement for stiff and heavy structures and a decreasing effect for other cases. Also, the shear forces of stories increased and decreased in the upper and lower stories, respectively, as a result of the mentioned mutual effect. Finally, the study indicated that under a sample ground motion, simultaneous impact and cross-interaction increased the ductility demand of stories for taller structures while it decreased the ductility demand of shorter buildings.
\end{abstract}

(C) 2020 Sharif University of Technology. All rights reserved.

\section{Introduction}

Increase in population and limited availability of habitable urban space have resulted in densely located buildings in most busy places. Concentration of tall buildings and skyscrapers in downtowns has made the occurrence of a special seismic phenomenon likely, namely pounding of adjacent structures. In the 1964 Alaska earthquake, the 14-story building of Westward Anchorage Hotel was damaged because of pounding to a shorter 6-story adjacent building. Despite a $10 \mathrm{~cm}$ gap, the impact was strong enough to displace the steel-

\footnotetext{
*. Corresponding author. Tel.: +98 3133913844 ;

Fax: + 98 3133912700

E-mail addresses: mehdi_kermani@yahoo.com ( $M$.

Kermani); mmsaadatpour@cc.iut.ac.ir (M.M. Saadatpour);

farhad@cc.iut.ac.ir (F.Behnamfar); mehdi@eng.ui.ac.ir (M. Ghandil)
}

doi: $10.24200 /$ sci.2019.5405.1255 girder roof of the shorter building [1]. In 1985 Mexico City and 1989 Loma Prieta earthquakes, a large share of seismic damage was also due to pounding.

The pounding between adjacent structures has generally been modeled using a special spring-damper contact element or the gap element, applying the principles of impact between rigid bodies and making use of a restitution factor. The examination of pounding of single-degree-of-freedom systems showed that the response was not overly sensitive to the restitution coefficient [2]. Also, the intensity of impact was larger for adjacent systems with different heights.

Seismic pounding between adjacent structures with different structural properties has been the subject of various research works, such as Dimitrakopoulos et al. [3], Polycarpou and Komodromos [4,5], Cole et al. [6], Jankowski [7], Efraimiadou et al. [8], Mahmoud et al. [9], and Polycarpou et al. [10], in which either the base has been taken to be rigid or through-the-soil interaction has been ignored. 
Soil-Structure Interaction (SSI) increases the vibration period and damping ratio, resulting in a rocking motion of buildings. When damping does not increase to the extent that it alleviates the effects of the increased period and the induced rocking motion, this combinatory phenomenon can lead to an increased displacement response and a higher possibility for pounding even if the code-prescribed distance is observed between buildings.

Exchange of seismic energy between side-by-side buildings occurs also through another route that is the underlying soil and is called the cross interaction coupling. Considering pounding and cross-interaction concurrently is not usual in seismic analysis, because each one is sufficiently complicated on its own. In one of the important studies on modeling cross-interaction using lumped parameters, an exact solution was used based on a time domain boundary element procedure. It considered two adjacent square foundations on a halfspace to derive stiffness and damping coefficients for modeling correlation between dynamic responses of the pair of foundations [11].

Pounding of two adjacent structures under the 1979 Montenegro earthquake including Structure-SoilStructure Interaction (SSSI) was studied [12]. The finite and boundary element methods were used for modeling of the structures and the soil. It was shown that SSSI effects on pounding could not be ignored. Chouw [13] analyzed two adjacent buildings linked by a pedestrian bridge accounting for flexibility of soil by employing the boundary element method in the Laplace and time domains. In the study of a bridge on soft soil [14] with SSI, it was concluded that the minimum distance at the expansion joint was a function of the shear wave velocity in soil. In another work, it was observed that SSI could considerably increase the number of impacts between bridge girders in an earthquake [15]. In two concurrent experimental research works, SSSI effects on pounding were studied $[16,17]$. In the first set of the tests, small samples of two adjacent structures were constructed from PVC and tested on a shaking table. It was shown that pounding was more probable when the soil was softer and the difference level between the two buildings was higher. In the second experiments, two adjacent blocks each time on a different type of stiff, medium, and soft soils were tested on a shaking table. Contrarily to the previous test, this time pounding was physically provided for. Again, more extensive impacts were observed when the difference of the two blocks was more. The nonlinear behavior of soil was observed to have an essential effect on pounding in bridges [18]. On such a soil, lateral displacement of adjacent decks was amplified and the amplification resulted in a larger impact.

In another study, a combination of spatial varia- tion of ground motion, the SSI, and the site effects was included [19]. It was shown that the code-prescribed width of the separation joint was not sufficient on soft soils, especially when the fundamental periods of the soil and structure were close to each other or equal. Naserkhaki et al. [20] investigated the simultaneous effects of pounding and SSSI. They developed a model consisting of adjacent shear buildings responding in elastic range and resting on equivalent springs and dampers. The pounding element was a viscoelastic zero-length member at story level. They compared the responses for two cases of fixed-base and flexiblebase conditions and concluded that pounding and SSSI altogether resulted in a more severe response.

The apparent importance of cross-interaction between adjacent structures on pounding and the very few relevant research works on the subject are the incentives of this study. In this work, first, the cases susceptible to pounding are identified using simple lumped parameter models of adjacent systems and then, a rigorous analysis is implemented for multistory structural models using ground motion records. The cases for which pounding should be a concern are introduced parametrically and the effects of pounding on seismic response are investigated. As advantages of the present work, the nonlinear behavior of structures is included and more detailed results on structural behavior, like distribution of story shears and story ductility demands, are presented.

\section{Basic theory of impact}

In the Poisson's model of impact, concepts such as forward impact, backward impact, and the restitution coefficient are used for the analysis of the impact of two moving masses [21]. In such a model, the total time of impact is divided into two phases. In phase one, the two approaching masses pound and squeeze each other finally to a zero relative velocity. The second phase begins with the two masses detaching from each other and returning. Therefore, the induced impulse is referred to as the impulse during the approach phase $\left(P_{A}\right)$ and the impulse during expansion phase of impact $\left(P_{R}\right)$. Accordingly, the restitution coefficient, $e$, is defined as:

$$
e=\frac{P_{R}}{P_{A}}, \quad 0<e<1 .
$$

Various mechanical models have been proposed for impact. Among them, the linear elastic model $(e=1)$, the plastic impact, the Hertz theory of impact, the nonlinear oscillator model, and the viscous impact model have been more widely used. The Hertz theory of impact was developed by Timoshenko and Goodier [22]. This theory has been shown to be an appropriate model for a stiff sphere impacting a thick plate at ordinary 
velocities. For softer materials and higher velocities, the effects of plastic deformations and strain rate must be considered. The viscous damping impact model utilizes a dashpot for dissipation of energy during impact. The restitution factor is only a function of damping ratio, $\xi$, in this model. For $\xi=0$, a perfectly elastic impact $(e=1)$ occurs. The relation between $e$ and $\xi$ is [2]:

$$
\begin{aligned}
& c=2 \xi \sqrt{k \frac{m_{1} m_{2}}{m_{1}+m_{2}}}, \\
& \xi=\frac{\ln (e)}{\sqrt{\pi^{2}+(\ln (e))^{2}}} .
\end{aligned}
$$

In Eq. (2), $c$ and $k$ are damping coefficient and stiffness factor of the contact surface and $m_{1}$ and $m_{2}$ are masses of the impacting bodies. The nonlinear oscillator model [23] is in fact an extension of the latter model to the nonlinear case. Here, the governing equations have to be solved numerically. If $D$ is a measure of damping and $v_{n}$ is the normal impact velocity, the restitution factor is determined by Eq. (3) as [23]:

$$
e=1-D v_{n}
$$

Due to its simplicity and possibility of implementation in the available Finite Element Method (FEM) software, the viscous damping model is selected to be implemented in this study.

\section{The impact model used}

As described above, the viscous damping model is used in this research. The impact element model is shown in Figure 1. It constitutes three sub-elements. In the middle part, a linear spring $k_{p}$ and a dashpot $c_{p}$ are present. On the right, there is a predefined gap. The spring $k_{p}$ is used for modeling elastic deformations at impact. The viscous damper $c_{p}$ defines a linear source of energy dissipation (due to heat, sound, etc.) at impact. The element is activated when the gap is closed. In Figure 1, $i$ and $j$ are the labels of the two nodes of the element. This element has an extension (contraction) degree of freedom at each node.

The force-displacement relationship of this element is shown in Figure 2. For modeling of pounding

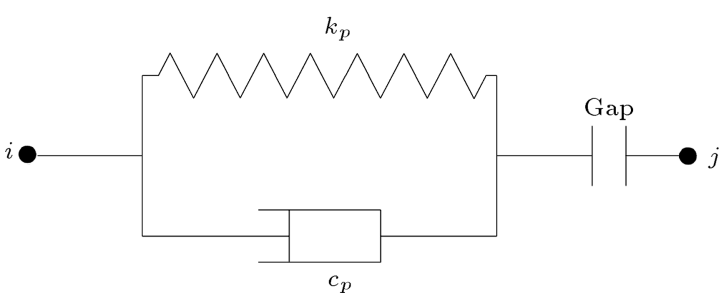

Figure 1. Pounding (impact) element.

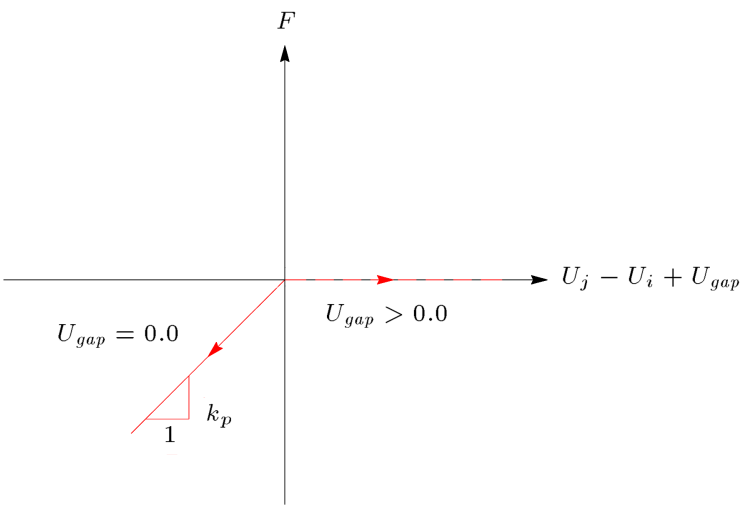

Figure 2. Force-displacement relationship for the pounding element $\left(u_{i}\right.$ and $u_{j}$ are displacements of nodes $i$ and $j$, respectively).

in the numerical analysis, label $i$ is assigned to the node subject to impact on one structure and label $j$ to the corresponding node on the adjacent structure.

\section{Parametric study of the pounding cases}

The simplified model of the two adjacent structures on flexible base is shown in Figure 3. Each of the two structures is considered as a single-degree-of-freedom system with a certain mass, mass height, rigid-base lateral stiffness, and damping. The lumped parameter model proposed by Mulliken and Karabalis is used to model the flexibility of soil with springs and dampers for horizontal and rotational degrees of freedom at the base [11]. In the parametric study, the properties of the soil springs and dampers as well as those of the structures are varied and different cases regarding the extent of SSI, cross-interaction, and distance between buildings are studied to identify the cases most likely subject to pounding. The pounding cases will be analyzed for nonlinear multi-story systems under earthquake loading in the next section.

\subsection{The analytical model}

The model under study with the degrees of freedom for each adjacent system is shown in Figure 3 . In Figure 3(a), $m_{i}, m_{b i}, I_{i}, I_{b i}, c_{i}, k_{i}$, and, $h_{i}(i=1,2)$ are the mass of the structure, total mass of the base (including foundation and the added mass of underlying soil), mass moment of inertia of structure, total mass moment of inertia of base (including foundation and the added inertia of underlying soil), damping of structure, lateral stiffness of structure, and height of the mass of structure, respectively. Also, the subscript $i$ is the label of structure (on the left, $i=1$ and on the right, $i=2$ ). Moreover, $k_{h}$ and $c_{h}, k_{h c}$ and $c_{h c}, k_{r}$ and $c_{r}$, and $k_{r c}$ and $c_{r c}$ are respectively the coefficients of soil stiffness and damping for horizontal, coupled horizontal, rocking, and coupled rocking motions. Therefore, the system of Figure 3 possesses six degrees of freedom, 


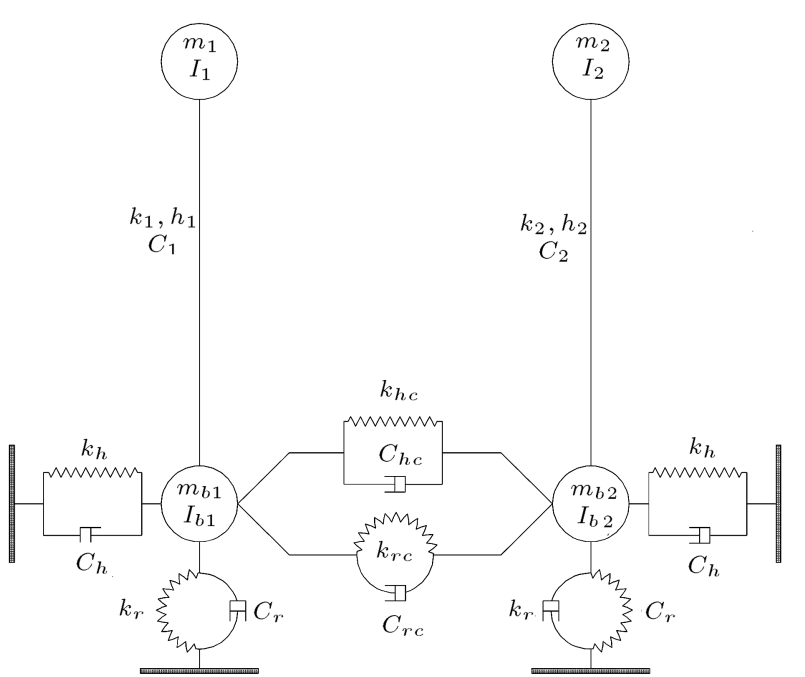

(a)

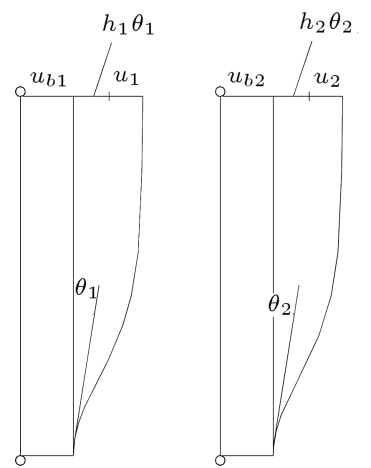

(b)

Figure 3. The model considered for the six-degrees-of-freedom system of two adjacent structures with cross interaction: (a) Analytical model, and (b) displacement diagram.

including the horizontal displacement of the mass of each structure relative to the base, $u_{i}$, due to rocking, $h_{i} \theta_{i}$ (where $\theta_{i}$ is rotation of base), and the horizontal displacement of base, $u_{b i}$, relative to free-field ground movement, $u_{g}$.

\subsection{Equations of motion under harmonic ground motion}

If the reference ground under the system of Figure 3 has a harmonic motion as $u_{g}=\bar{u}_{g} e^{i \omega t}$, where $\bar{u}_{g}(\omega)$ is the amplitude of motion for the excitation frequency $\omega$, the equations of motion can be written as:

$$
\begin{aligned}
& m_{1}\left(\ddot{u}_{1}+\ddot{u}_{b 1}+h_{1} \ddot{\theta}_{1}\right)+c_{1} \dot{u}_{1}+k_{1} u_{1}=m_{1} \ddot{u} g, \\
& m_{1}\left(\ddot{u}_{1}+\ddot{u}_{b 1}+h_{1} \ddot{\theta}_{1}\right)+m_{b 1} \ddot{u}_{b 1}+c_{h} \dot{u}_{b 1} \\
& \quad+c_{h_{c}}\left(\dot{u}_{b 1}-\dot{u}_{b 2}\right)+k_{h} u_{b_{1}}+k_{h c}\left(u_{b_{1}} \quad u_{b 2}\right) \\
& =-\left(m_{1}+m_{b 1}\right) \ddot{u}_{g}, \\
& m_{1}\left(\ddot{u}_{1}+\ddot{u}_{b 1}+h_{1} \ddot{\theta}_{1}\right) h_{1}+\left(I_{1}+I_{b 1}\right) \ddot{\theta}_{1}+c_{r} \dot{\theta}_{1} \\
& +c_{r c}\left(\dot{\theta}_{1} \quad \dot{\theta}_{2}\right)+k_{r} \theta_{1}+k_{r c}\left(\theta_{1} \quad \theta_{2}\right) \\
& =m_{1} h_{1} \ddot{u}_{g}, \\
& m_{2}\left(\ddot{u}_{2}+\ddot{u}_{b 2}+h_{2} \ddot{\theta}_{2}\right)+c_{2} \dot{u}_{2}+k_{2} u_{2}=m_{2} \ddot{u}_{g}, \\
& m_{2}\left(\ddot{u}_{2}+\ddot{u}_{b 2}+h_{2} \ddot{\theta}_{2}\right)+m_{b 2} \ddot{u}_{b 2}+c_{h} \dot{u}_{b 2} \\
& \quad+c_{h c}\left(\dot{u}_{b 2}-\dot{u}_{b 1}\right)+k_{h} u_{b_{2}}+k_{h c}\left(u_{b_{2}} u_{b 1}\right) \\
& =-\left(m_{2}+m_{b 2}\right) \ddot{u}_{g},
\end{aligned}
$$

$$
\begin{aligned}
m_{2}\left(\ddot{u}_{2}\right. & \left.+\ddot{u}_{b 2}+h_{2} \ddot{\theta}_{2}\right) h_{2}+\left(I_{2}+I_{b 2}\right) \ddot{\theta}_{2}+c_{r} \dot{\theta}_{2} \\
& +c_{r c}\left(\dot{\theta}_{2}-\dot{\theta}_{1}\right)+k_{r} \theta_{2}+k_{r c}\left(\theta_{2}-\theta_{1}\right) \\
= & m_{2} h_{2} \ddot{u}_{g} .
\end{aligned}
$$

It is preferred in this study to develop and utilize the non-dimensional form of the above equations. Accordingly, it can be shown that the above equations are summarized in matrix form as:

$$
\left(\hat{K}+i \beta \hat{C}+\beta^{2} \hat{M}\right) \bar{u}=\bar{P},
$$

in which $\bar{u}(\omega)=\left\{\bar{u} 1, \bar{u} b 1, h 1 \bar{\theta}_{1}, \bar{u} 2, \bar{u} b 2, h 2 \bar{\theta}_{2}\right\} T$ is the vector of amplitudes of the harmonic response $u=$ $\bar{u}_{e i} \omega t, \omega$ is the natural frequency of the system, $\beta=$ $\omega / \omega_{1}, \omega_{1}=\sqrt{k_{1} / m_{1}}$, and the matrices $\hat{K}, \hat{C}$, and $\hat{M}$ and the vector $\bar{P}$ are given in Appendix A. The entries of the above matrices are functions of the following parameters:

$$
\bar{s}_{i}=\omega_{i} h_{i} / c_{s}
$$

where $\bar{s}_{i}$ is the ratio of the lateral stiffness of structure $i$ with rigid base to the stiffness of soil, $\omega_{i}$ is the natural frequency of rigid-base structure $i$, and $c_{s}$ is the shear wave velocity in soil. Also:

$$
\bar{m}_{i}=m_{i} /\left(\rho a^{2} h_{i}\right)
$$

where $\bar{m}_{i}$ is the mass ratio of structure $i$ to the soil, $\rho$ is mass density of soil, and $a$ is half width of rigid square foundation. Moreover:

$$
\bar{h}_{i}=h_{i} / a
$$


Table 1. Equations for lumped parameter values of uncoupled stiffness, damping, and mass properties of the base* [11].

\begin{tabular}{cccccc}
\hline $\begin{array}{c}\text { Motion } \\
\text { component }\end{array}$ & $\begin{array}{c}\text { Damping } \\
\boldsymbol{c}\end{array}$ & $\begin{array}{c}\text { Stiffness } \\
\boldsymbol{k}\end{array}$ & $\begin{array}{c}\text { Equivalent } \\
\text { soil mass } \\
\boldsymbol{m}_{\boldsymbol{v}}\end{array}$ & $\begin{array}{c}\text { Equivalent } \\
\text { radius } \\
\boldsymbol{r}_{\mathbf{0}}\end{array}$ & $\begin{array}{c}\text { Mass ratio } \\
\overline{\boldsymbol{\beta}}\end{array}$ \\
$\begin{array}{c}\text { Horizontal } \\
(\boldsymbol{h})\end{array}$ & $\frac{0.163 k}{c_{s}} a$ & $\frac{9.2 G a}{2}$ & $\frac{0.095 m}{\bar{\beta}}$ & $\frac{2 a}{\sqrt{\pi}}$ & $\frac{(7-8 v) m}{(1) v) \rho r_{0}^{3}}$ \\
$\begin{array}{c}\text { Rocking } \\
(\boldsymbol{r})\end{array}$ & $\frac{0.6}{c_{s}} a k$ & $\frac{4 G a^{3}}{1}$ & $\frac{0.24 m}{\beta}$ & $\frac{2 a}{\sqrt[4]{3 \pi}}$ & $\frac{3(1-v) m}{8\left(r_{0}^{5}\right) \rho}$ \\
\hline$* c_{s}=\sqrt{G / \rho}$ is the shear wave velocity in soil $(G:$ shear modulus) and $\nu$ is Poisson's ratio of soil.
\end{tabular}

Table 2. Coupled stiffness and damping coefficients [11].

\begin{tabular}{ccccc}
\hline $\begin{array}{c}\text { Motion } \\
\text { component }\end{array}$ & $\begin{array}{c}\text { Stiffness } \\
\boldsymbol{k}_{\boldsymbol{c}}\end{array}$ & $\begin{array}{c}\text { Damping } \\
\boldsymbol{c}_{\boldsymbol{c}}\end{array}$ & $\boldsymbol{\Gamma}$ & $\boldsymbol{\psi}$ \\
\hline $\begin{array}{c}\text { Horizontal } \\
(\boldsymbol{h})\end{array}$ & $\frac{G a}{2-\nu} \Gamma$ & $\frac{G a^{2}}{c_{s}(2-\nu)} \psi$ & $3.7561 \times 10^{-0.18995(d / a)}$ & 13.2875 \\
$\begin{array}{c}\text { Rocking } \\
(\boldsymbol{r})\end{array}$ & $\frac{G a^{3}}{1-\nu} \Gamma$ & $\frac{G a^{4}}{c_{s}(1-\nu)} \psi$ & $\left(0.04234-0.2396 \log _{10}^{d / a}\right)$ & $\left(7.3823-6.775 \log _{10}^{d / a}\right)$ \\
\hline
\end{tabular}

in which $\bar{h}_{i}$ is the aspect ratio of structure $i$. The lumped parameter stiffness, damping, and mass properties of the base are given in Table 1 for uncoupled and in Table 2 for coupled parameters.

The values in Tables 1 and 2 should indeed be dependent on the excitation frequency. For simplicity and making the calculation in the time domain practically possible, a least squares technique has been adopted from [11] based on exact values derived by the boundary element method. This guarantees the minimum error in SSI response calculation with the values given in Tables 1 and 2 .

It is to be noted that no pounding is considered in Eq. (10). The purpose of studying the response of the system using the above equations is identifying the cases with the highest possibilities of pounding. Accordingly, in the nonlinear dynamic analysis of the system under ground motion, only such cases will be investigated. This procedure prevents examining irrelevant cases.

\subsection{Numerical analysis of free vibration}

The system was analyzed for undamped free vibration using Eq. (10) by omitting the damping matrix and the load vector on the right side. As described before, in Eq. (10), the parameters $\bar{s}_{i}, \bar{h}_{i}, \bar{m}_{i}$ (Eqs. (12)-(14), $i=1,2)$ as well as $\bar{d}=d / a, \xi$, and $v$ are involved. The damping ratio, $\xi$, which is not involved in free vibration analysis, is taken equal to 0.05 for both rigid-base structures in the subsequent forced vibration analysis. The dynamic response is not much sensitive to the Poisson's ratio of soil and it is set to 0.35 .

The parameter $\bar{s}_{i}$ shows the ratio of rigid-base stiffness of structure $i$ to that of the underlying soil. This parameter often takes values between 0.1-10 [24].
Larger $\bar{s}_{i}$ values show a stiffer structure and a softer soil, representing a higher interaction. The same values are used in this study; however, for the sake of conciseness and brevity, only the results for $\bar{s}_{i}$ equal to 0.75 and 10 representative of all cases will be presented. In Eq. (11), $\omega_{i}$ is the natural frequency of each structure when the base is rigid. Accordingly, the natural period is $T_{i}=2 \pi / \omega_{i}$ and it is assumed that:

$$
T_{i}=c_{t} h_{i}^{3 / 4}
$$

where $c_{t}$ is a coefficient dependent on the type of the lateral load bearing system. Calculating $T_{i}$ from Eq. (14) will yield $\omega_{i} \cdot \bar{m}_{i}$ is the mass ratio of structure $i$ to an underlying soil with the same volume. Larger values of $\bar{m}_{i}$ show larger inertial loads applied by the structure to soil and therefore, more extensive SSI. $\bar{h}_{i}$ is a measure of slenderness of structure $i$. A larger $\bar{h}_{i}$ shows higher importance of rocking motion in the overall response of the structure. In this study, for massive and short buildings (like power plants), $\bar{m}_{i}=$ 5.0 and $\bar{h}_{i}=0.3$, and for light (low density) and tall buildings (such as multistory structures), $\bar{m}_{i}=0.3$ and $\bar{h}_{i}=5.0[24]$.

The parameter $\beta_{0}=\omega_{2} / \omega_{1}$ showing the ratio of rigid-base natural frequencies of two structures is also used. Values 1,2 , and 3 for $\beta_{0}$ were studied, but since low sensitivity was observed, only the results for $\beta_{0}=2$ are given. The parameter $\bar{d}=d / a$ representing the distance ratio of the two buildings is a key factor for studying the effects of adjacency ( $d$ is the clear distance between the adjacent foundations/buildings). Here, it is supposed that $\bar{d}=0-10$, ranging from full contact to no cross-interaction cases.

The stiffness matrix of Eq. (10) given in Appendix $\mathrm{A}$ is generally non-symmetric, except when the 
two structures are the same. Therefore, the averages of the associated non-diagonal elements are used in their places to keep the eigen-value problem in its real form.

Results from calculating the natural frequency ratio $\beta_{j}=\omega_{j} / \omega_{1}$ as a function of $\bar{d}$, where $\omega_{j}$ 's are natural frequencies $(j=1, \cdots, 6)$ of the system in Figure 3, are shown in Figures $4-7$. To include also the effect of clear distance, each $\beta_{j}$ is normalized to its value for large distances, i.e. when the cross-interaction is almost diminished. Figures 4 and 5 are for the lowSSI case $\left(\bar{s}_{1}=0.75\right.$, refer to the first paragraph of this section), i.e. when the effect of SSI is not important, and Figures 6 and 7 correspond to the opposite case, i.e. high SSI $\left(\bar{s}_{1}=10.0\right)$. Also, Figures 4 and 6 represent light and tall buildings and Figures 5 and 7 are for massive and short structures. It is observed in Figure 4 that for low SSI, the frequency of rocking motion of

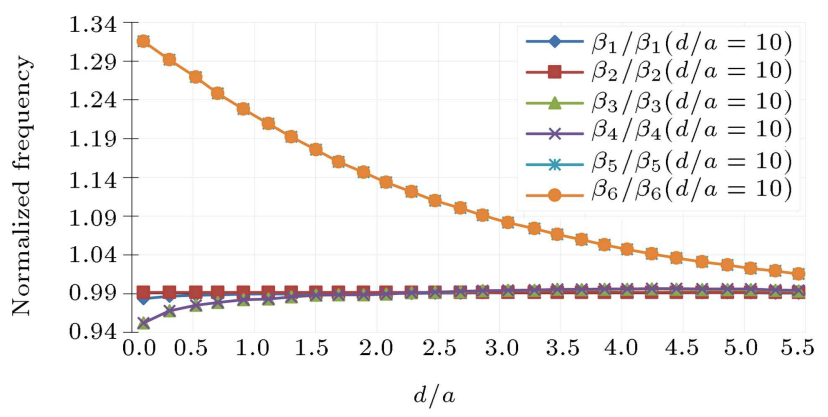

Figure 4. Variation of natural frequency ratios with clear distance for $\bar{h}_{1}=5.0, \bar{m}_{1}=0.3, \bar{s}_{1}=0.75$, and $\beta_{0}=2.0$.

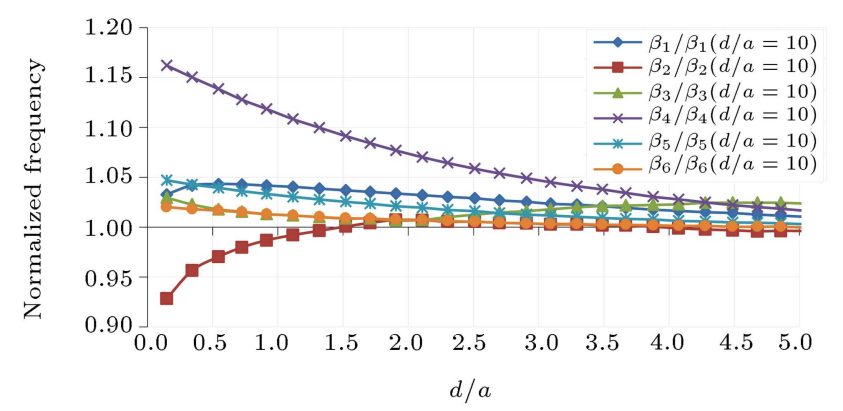

Figure 5. Variation of natural frequency ratios with clear distance for $\bar{h}_{1}=0.3, \bar{m}_{1}=5.0, \bar{s}_{1}=0.75$, and $\beta_{0}=2.0$.

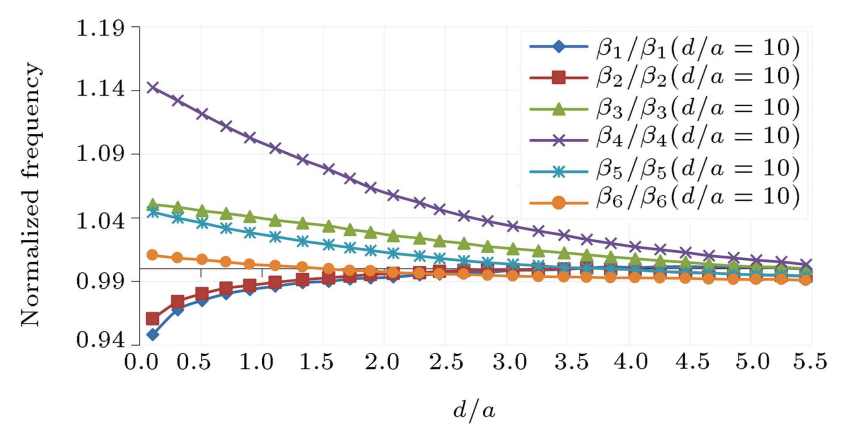

Figure 6. Variation of natural frequency ratios with clear distance for $\bar{h}_{1}=5.0, \bar{m}_{1}=0.3, \bar{s}_{1}=10.0$, and $\beta_{0}=2.0$.

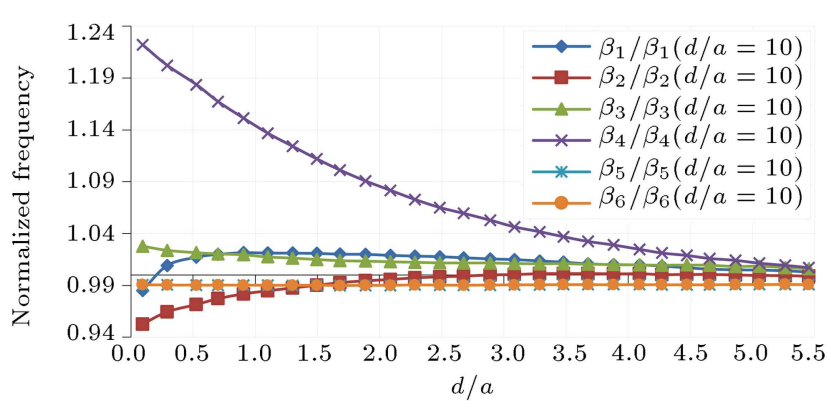

Figure 7. Variation of natural frequency ratios with clear distance for $\bar{h}_{1}=0.3, \bar{m}_{1}=5.0, \bar{s}_{1}=10.0$, and $\beta_{0}=2.0$.

light and tall buildings is much affected for $\bar{d}<2$ and it increases by $34 \%$ at maximum. For short and massive buildings in Figure 5, the frequency related to horizontal motion of the base shows maximum sensitivity for $\bar{d}<3$ with a maximum increase of $16 \%$. It is to be mentioned that associating each frequency with a governing motion in the system was done by examining the associated mode shapes not shown here for brevity. The interested reader may refer to a comprehensive study of the mode shapes of the coupled systems $[25,26]$.

For high-SSI cases, in Figures 6 and 7, more or less the same behavior with different intensities was observed. The increase in the rocking motion frequency for the tall building case was $15 \%$ at maximum and that of the base horizontal motion for short buildings was up to $24 \%$ while, generally, the modal damping associated with the horizontal and rocking motions of the base was relatively high, which resulted in lower contribution of the corresponding modes to total response of the system. Figures $4-7$ show that for $\bar{d}>5$, cross-interaction between adjacent buildings can be neglected.

Also, it was observed that the greatest effect of adjacency of buildings was on the natural frequencies belonging to the motions at the base, namely horizontal translation and rocking, which was increasing. For low SSI, this effect was more pronounced for tall buildings and mostly affected the rocking motion. On the other hand, for high SSI, the increase was larger for short buildings and affected the base horizontal motion. Results of analysis for other $\bar{s}_{i}$ and $\beta_{0}$ values are given elsewhere [27].

\subsection{Analysis of harmonic base motion}

According to Eq. (10), a horizontal harmonic motion of $u_{g}(\omega, t)=\bar{u}_{g}(\omega) e^{i \omega t}$ was applied to the rigid reference to which the uncoupled springs and dampers of Figure 3 were connected. This represents the motion at the bedrock.

The total displacement amplitude, $\bar{u}_{i}^{t}$, is calculated from Eq. (15):

$$
\bar{u}_{i}^{t}=\bar{u}_{i}+\bar{u}_{b_{i}}+h_{i} \bar{\theta}_{i}+\bar{u}_{g}
$$

where the involving terms are defined under Eq. (10). 


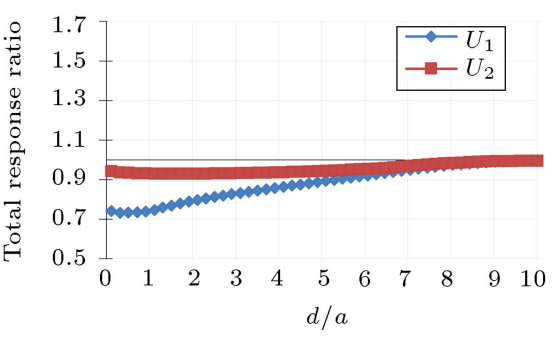

(a)

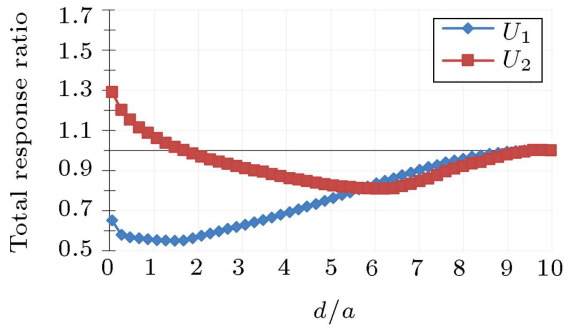

(c)

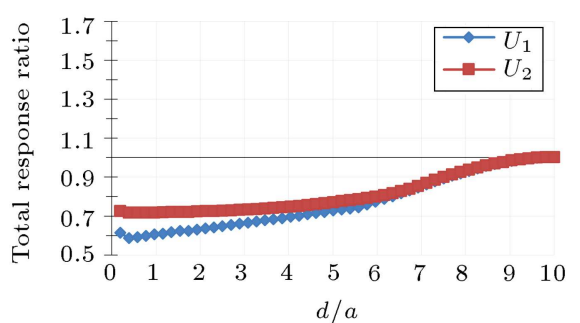

(b)

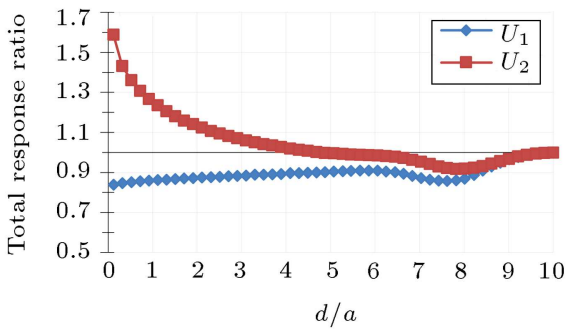

(d)

Figure 8. Total response ratios for structures 1 and 2 for $\bar{h}_{1}=5.0, \bar{m}_{1}=0.3$, and $\beta_{0}=2.0$ : (a) $\bar{s}_{1}=0.75$, (b) $\bar{s}_{1}=1.25$, (c) $\bar{s}_{1}=2.50$, and (d) $\bar{s}_{1}=5.00\left(U_{i}=\left|\bar{u}_{i}^{t}\right| /\left|\bar{u}_{i}^{t}\right|_{(\bar{d}=10.0)}, i=1,2\right)$.

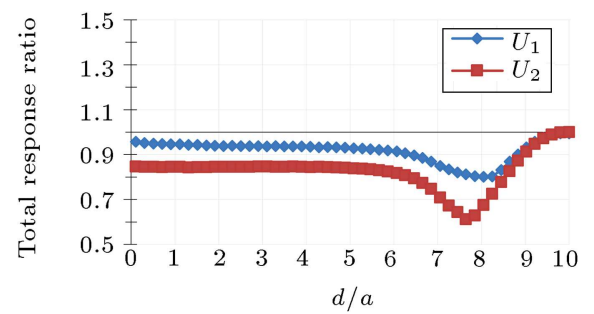

(a)

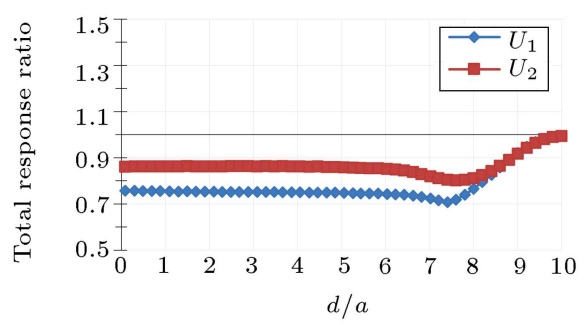

(c)

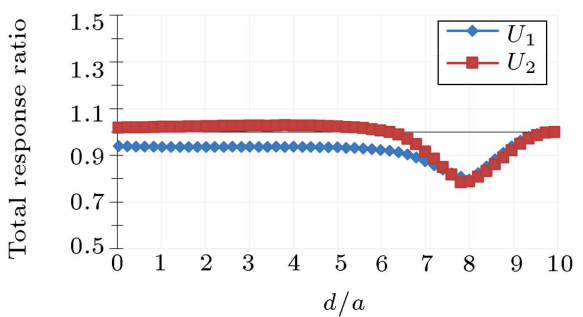

(b)

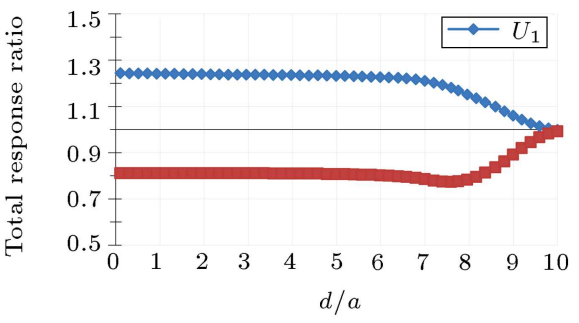

(d)

Figure 9. Total response ratios for structures 1 and 2 for $\bar{h}_{1}=0.3, \bar{m}_{1}=5.0$, and $\beta_{0}=2.0$; (a) $\bar{s}_{1}=0.75$, (b) $\bar{s}_{1}=1.25$, (c) $\bar{s}_{1}=2.50$, and (d) $\bar{s}_{1}=5.00\left(U_{i}=\left|\bar{u}_{i}^{t}\right| /\left|\bar{u}_{i}^{t}\right|_{(\bar{d}=10.0)}, i=1,2\right)$.

The absolute values of displacement responses of the structural masses (Figure 3 ) with respect to those of the no cross-interaction case $(\bar{d}=10)$ are shown in Figures 8 and 9 . The cases of tall and short buildings for low to high SSI values are given. Figures 8 and 9 indicate that the response of the system has a stronger sensitivity to adjacency than to natural frequencies. The maximum response variation relative to no crossinteraction for tall buildings occurred at medium values of $\bar{s}_{1}$ (intermediate SSI) and for short buildings at larger values of $\bar{s}_{1}$. In the latter case, the maximum response ratio of structure 1 was $70 \%$ larger than that of the no-adjacency case.
In Figure 10, the relative lateral displacements of the structures are shown to identify pounding cases.

For this purpose, first, the relative displacement amplitude, $\bar{u}_{r}$, is calculated from Eq. (16):

$$
\bar{u}_{r}=\begin{array}{ll}
\left|\bar{u}_{1}^{t}\right| \quad\left|\bar{u}_{2}^{t}\right||\leftrightarrow 0 \leq| \operatorname{Arg}\left(\bar{u}_{1}^{t}\right) \mid & \left|\operatorname{Arg}\left(\bar{u}_{2}^{t}\right)\right| \leq \frac{\pi}{2} \\
\left|\bar{u}_{1}^{t}\right|+\left|\bar{u}_{2}^{t}\right| \leftrightarrow \frac{\pi}{2} \leq\left|\operatorname{Arg}\left(\bar{u}_{1}^{t}\right)\right| & \left|\operatorname{Arg}\left(\bar{u}_{2}^{t}\right)\right| \leq \pi(16)
\end{array}
$$

where $\operatorname{Arg}\left(\bar{u}_{i}^{t}\right)=\operatorname{Arctg}\left[\frac{\operatorname{Im}\left(\bar{u}_{i}^{t}\right)}{\operatorname{Re}\left(\bar{u}_{i}^{t}\right)}\right]$ and $I_{m}$ and $R_{e}$ show the imaginary and real parts $(i=1,2)$. Now, if $\bar{u}_{r}>d$, pounding occurs. Then, the condition for pounding is: $\bar{u}_{r}>d \quad$ or $\quad \bar{u}_{r} / \bar{u}_{g}>d / \bar{u}_{g} \quad$ or $\quad \bar{u}_{r} / \bar{u}_{g}>\bar{d}\left(a / \bar{u}_{g}\right)$ 


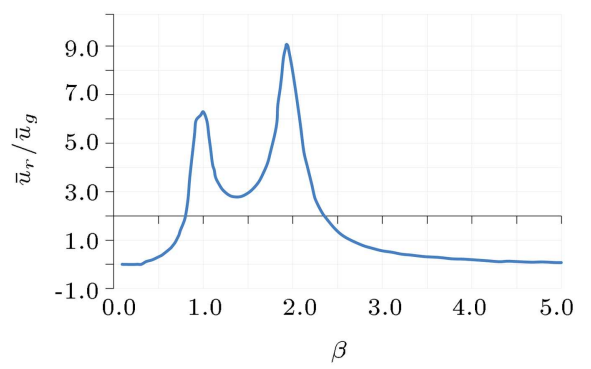

(a)

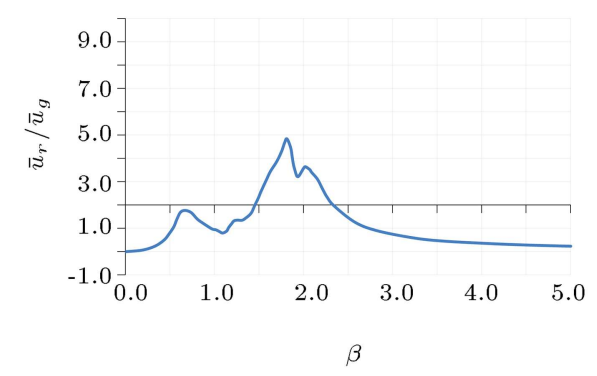

(c)

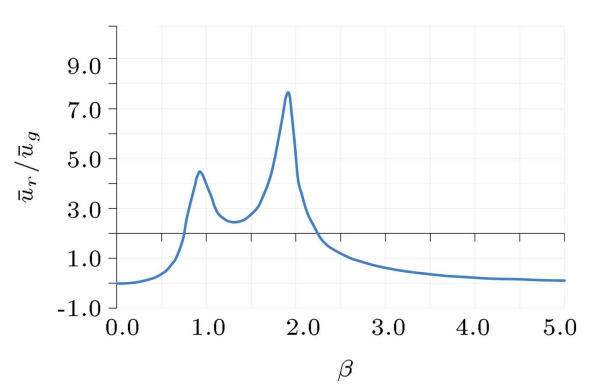

(b)

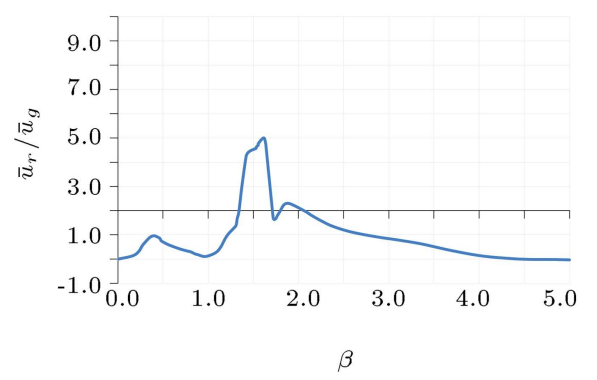

(d)

Figure 10. Possibility of pounding for tall buildings, $\bar{h}_{1}=5.0, \bar{m}_{1}=0.3, \bar{d}=0.1$, and $\beta_{0}=2.0$ : (a) $\bar{s}_{1}=0.75$, (b) $\bar{s}_{1}=1.25$, (c) $\bar{s}_{1}=2.50$, and (d) $\bar{s}_{1}=5.00$.

Therefore, $\bar{u}_{r}$ can be depicted with frequency for a constant $\bar{d}$ if $a / \bar{u}_{g}$ is known. For instance, for a $20 \times 20 \mathrm{~m}$ foundation and an amplitude of $0.5 \mathrm{~m}$ in the horizontal base motion, $a / \bar{u}_{g}=20$. Then, if $\bar{u}_{r} / \bar{u}_{g}>20 \bar{d}$, pounding occurs.

Variation of $\bar{u}_{r} / \bar{u}_{g}$ with nondimensional frequency $\beta=\omega / \omega_{1}$, where $\omega$ stands for the frequency of harmonic excitation, is shown in Figure 10 for tall buildings with different values of $\bar{s}_{1}$ and $\bar{d}=0.1$. The intersection of horizontal and vertical axes in each figure shows the value of $\bar{d}\left(a / \bar{u}_{g}\right)$ on the vertical axis. For different values of $a / \bar{u}_{g}$, the horizontal axis can simply be moved up or down, consistently. Referring to the above discussion, pounding occurs when the curve is above the horizontal axis. This occurs more for smaller $\bar{d}$, smaller $a$, and larger $\bar{u}_{g}$. For tall buildings (Figure 10), the range of frequencies at which pounding is possible is the widest for low SSI (smaller values of $\bar{s}_{1}$ ). On the contrary, for short buildings, the range of frequencies possible for pounding reaches its widest value for higher SSI (larger values of $\bar{s}_{1}$ ) (not shown for brevity).

Therefore, SSSI reduces the possibility of pounding for taller buildings. The interesting point is that pounding is most probable for excitation frequencies about those of each rigid-base structure. Thus, the larger the $\beta_{0}$, the wider is the frequency range of pounding. In Figure 10, the frequency ratio ranges corresponding to pounding for $\bar{s}_{1}=0.75,1.25,2.5$, and 5 , are $0.80-2.30,0.75-2.25,1.45-2.32$, and $1.34-$ 2.08 , respectively. The band of the pounding frequency ratio is wider for smaller $\bar{s}_{1}$.

\section{Pounding analysis of multistory buildings}

\subsection{Equations of motion}

The parametric study in the previous sections bears the value of illuminating the cases for which pounding is possible. This fact is utilized in this section to select multistory building cases for nonlinear dynamic analysis. The approach to such a complicated problem can take two different viewpoints:

1. Real 3D structures with modeling all the details of the structural system;

2. Simple 2D systems retaining only the essential characteristics of the rigorous system.

While the first approach can give more accurate results, the physical meaning can be obscured by the presence of so many parameters involved. On the other hand, the second approach, while being approximate, can result in a better understanding of the reasons for the specific dynamic behavior of the system. Therefore, in this study, the second approach is adopted.

The general model used for the analysis in this section is shown in Figure 11. In this figure, each building is modeled with a $2 \mathrm{D}$ shear frame, i.e. rigid floors and flexible columns. The properties of the rigid floors are mass $m_{i}$, mass moment of inertia $I_{i}$, and height above base $h_{i}$. The flexible columns can behave nonlinearly. Their nonlinear behavior is assumed to be elastoplastic as shown in Figure 12 . The soil underneath the buildings is modeled using the equivalent linear approach [26]. 


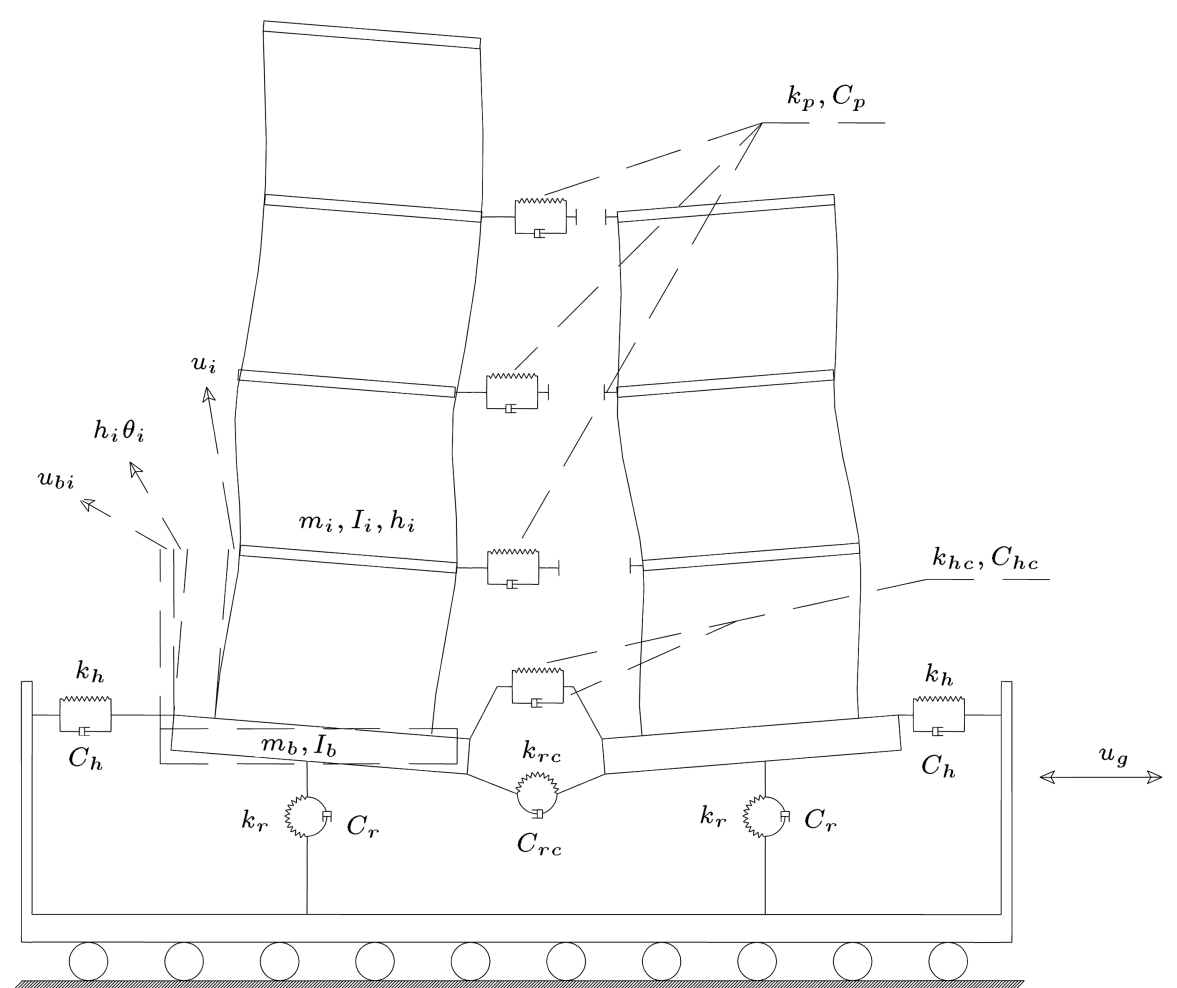

Figure 11. System of two adjacent multistory structures with Soil-Structure Interaction (SSI), cross-interaction, and pounding elements.

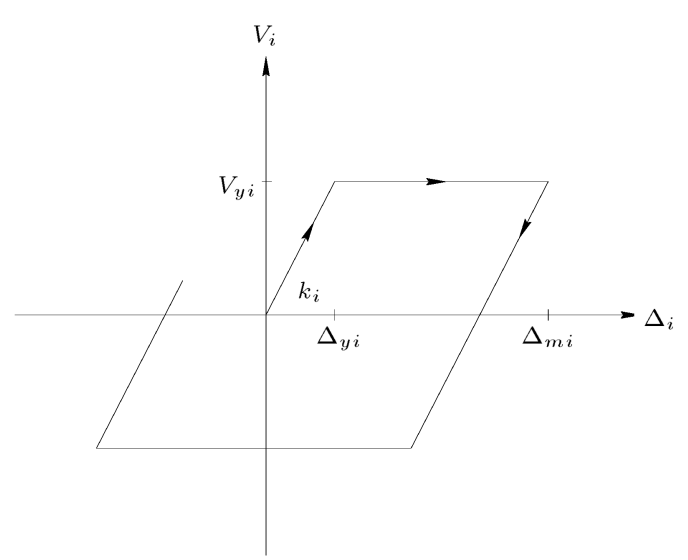

Figure 12. Elastoplastic behavior of columns.

The parameters needed for nonlinear modeling of columns are lateral stiffness for no rotation at nodes, $k$, and yield shear capacity, $V_{y}$. Accordingly, the ductility demand for each column, $\mu$, can be calculated as follows:

$$
\mu=\frac{\Delta_{m}}{\Delta_{y}}=\frac{k \Delta_{m}}{V_{y}} .
$$

$\Delta_{m}$ and $\Delta_{y}$ are the maximum and the yield drifts of column, respectively, calculated in the nonlinear dynamic analysis. $V_{y}$ is determined from Eq. (19):

$$
V_{y}=k \Delta_{y}
$$

The properties of soil springs and dampers in Figure 11 are taken from Tables 1 and 2 as discussed before. The pounding element shown in Figure 1 is introduced at each story level. The governing equation of motion of each story is:

$$
\begin{gathered}
m_{j} \ddot{u}_{j}^{t}+f_{D j} \quad f_{D j+1}+f_{s j} \quad f_{s j+1} \pm f_{p j}=0 \\
j=1, \cdots, n_{i}, \quad i=1,2,
\end{gathered}
$$

where $m_{j}$ is mass of the $j$ th level, $n_{i}$ is number of stories of structure $i, \ddot{u}_{j}^{t}$ is the total acceleration of the $j$ th level as:

$$
\ddot{u}_{j}^{t}=\ddot{u}_{j}+\ddot{u}_{b i}+h_{j} \ddot{\theta}_{i}+\ddot{u}_{g}
$$

with $i=1$ for the left and $i=2$ for the right structure; a double dot shows the acceleration. Also, damping force, $f_{D j}$, of the $j$ th story is calculated as:

$$
f_{D j}=c_{j}\left(\dot{u}_{j}-\dot{u}_{j} \quad 1\right),
$$

and the elastic spring force, $f_{s j}$, at the $j$ th story is:

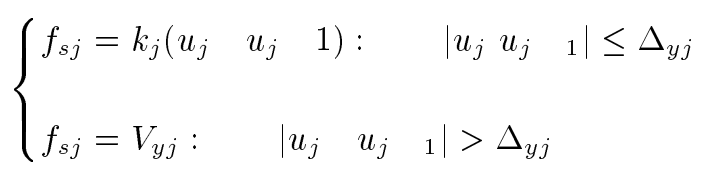

where $\Delta_{y j}$ and $V_{y j}$ are the yield drift and yield shear capacity of story $j$. In Eq. (20), the sign before $f_{p j}$ is plus for $i=1$ and minus for $i=2$ and: 


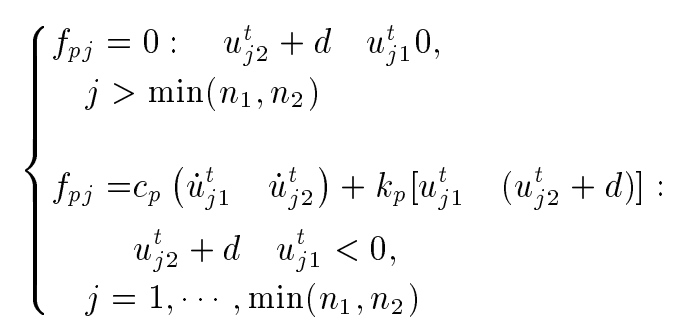

where $f_{p j}$ is the pounding force at the $j$ th story, $u_{j 1}^{t}$ and $u_{j 2}^{t}$ are the total lateral displacements of the $j$ th stories of structures 1 and 2, respectively, calculated by an equation similar to Eq. (15) dropping bars and taking account of $k_{p}$ and $c_{p}$ as spring and damper coefficients of the pounding element (Figure 1). The value of $k_{p}$ depends on the stiffness of colliding bodies. As in this study the same floor heights are assumed for the adjacent buildings, collision will be between rigid bodies and $k_{p}$ must be taken to be very large. The results of the time history analysis in this study were insensitive to $k_{p} \geq 10^{10} \mathrm{~N} / \mathrm{m}$. Therefore, $k_{p}=$ $10^{10} \mathrm{~N} / \mathrm{m}$ was assumed. Also, for the viscoelastic pounding element used in this study, the damping coefficient $c_{p}$ can be calculated from Eq. (2), in which the value of damping ratio, $\xi$, is set to 0.05 and $m_{1}$ and $m_{2}$ are masses of the two impacting adjacent stories.

The equation of motion of the whole body of each structure, including its foundation, in the horizontal direction is:

$$
\begin{aligned}
& \sum_{j=1}^{n_{i}} m_{j} \ddot{u}_{j}^{t}+m_{b i}\left(\ddot{u}_{b i}+\ddot{u}_{g}\right)+c_{h i} \dot{u}_{b i}+k_{h i} u_{b i} \\
& \quad \pm c_{h c}\left(\begin{array}{ll}
\dot{u}_{b 1} & \left.\dot{u}_{b 2}\right) \pm k_{h c}\left(u_{b 1} \quad u_{b 2}\right) \pm \sum_{j=1}^{n_{i}} f_{p j}=0 \\
\quad i=1,2
\end{array}\right.
\end{aligned}
$$

in which again where the \pm sign appears, it is plus for $i=1$ and minus for $i=2$. Finally, the equation of motion of each structure including its foundation in rocking motion is:

$$
\begin{aligned}
& \sum_{j=1}^{n_{i}} I_{j} \ddot{\theta}_{i}+I_{b i} \ddot{\theta}_{i}+\sum_{j=1}^{n_{i}} m_{j} \ddot{u}_{j}^{t} h_{j}+c_{r i} \dot{\theta}_{i}+k_{r i} \theta_{i} \\
& \pm c_{r c}\left(\begin{array}{ll}
\dot{\theta}_{1} & \dot{\theta}_{2}
\end{array}\right) \pm k_{r c}\left(\theta_{1} \quad \theta_{2}\right) \pm \sum_{j=1}^{n_{i}} f_{p j} h_{j}=0 \\
& i=1
\end{aligned}
$$

where the \pm sign rule is similar to Eq. (25). The system of Eqs. (20)-(26) is highly nonlinear due to yielding at columns and opening/closing of the gaps. This is the reason why the system in Figure 11 is selected to be $2 \mathrm{D}$ with rigid floors. A Rayleigh damping matrix for each rigid-base structure is considered. The constant accel- eration scheme of the Newmark numerical integration algorithm is used for implicit solution of the response. Because of different nonlinearities involved, the time step $\Delta_{t}$ has to be chosen with great care. If the effect of pounding elements is disregarded, $\Delta_{t} \leq 0.1 T_{n}$ is sufficient, where $T_{n}$ is the smallest important period of the system. However, whenever a pounding element is activated, much smaller $\Delta_{t}$ 's are required to follow the attach-detach process at the corresponding floor. This requires selecting a $\Delta_{t}$ as small as $[0.001 \sim 0.00001] T_{n}$, which considerably adds to the computation time and is in evitable.

\subsection{Dynamic characteristics}

The characteristics of the system of Figure 11 should be taken such that pounding can occur in reality so that its effects can be studied. The cases for which occurrence of pounding is a strong possibility were shown in Figure 10. If number of stories is $\mathrm{n}$ and interstory height is $3 \mathrm{~m}$, then combining Eqs. (11) and (14) results in:

$$
n=\frac{1}{3}\left(\frac{\bar{s} c_{t} c_{s}}{2 \pi}\right)^{4} \text {. }
$$

The factor $c_{t}$ is 0.07 for an $\mathrm{RC}$ frame. The variation of $n$ with $c_{s}$ and $\bar{s}$ is shown in Figure 13 .

The same information is presented in Table 3 for reference. In Table 3, $T$ is the fixed-base first-mode structural period that is determined from Eq. (14) or eigen-value analysis. To decrease the computation

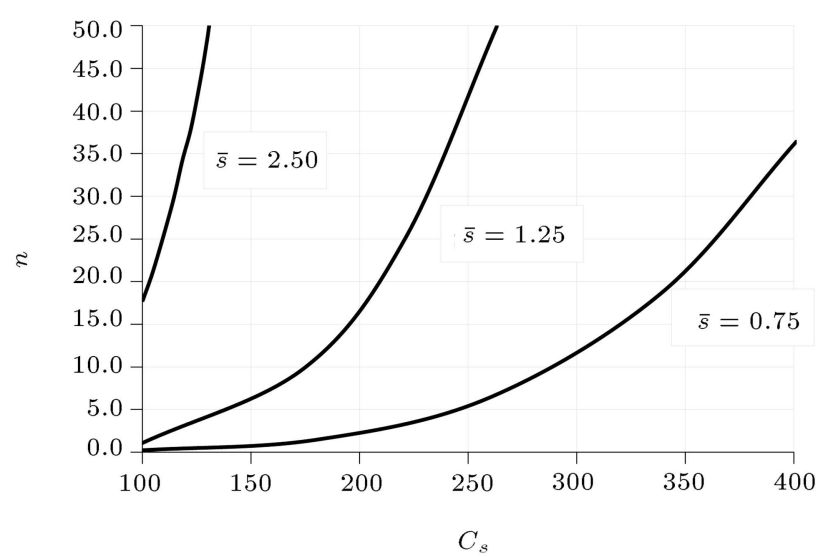

Figure 13. Variation of number of stories $(n)$ as a function of soil-structure stiffness ratio $(\bar{s})$ and shear wave velocity $\left(c_{s}\right)$.

Table 3. Consistent values of $\bar{s}, n, c_{s}$, and $T$ (Eqs. (27) and (14)).

\begin{tabular}{cccc}
\hline$\overline{\boldsymbol{s}}$ & $\begin{array}{c}\text { Number of stories } \\
(\boldsymbol{n})\end{array}$ & $\begin{array}{c}\boldsymbol{c}_{\boldsymbol{s}} \\
(\mathbf{m} / \mathbf{s})\end{array}$ & $\begin{array}{c}\boldsymbol{T} \\
(\mathbf{s e c})\end{array}$ \\
\hline 0.75 & $0-20$ & $100-300$ & $0-1.5$ \\
1.25 & $0-20$ & $100-199$ & $0-1.5$ \\
2.5 & 20 & 100 & 1.5 \\
\hline
\end{tabular}


time, it is desired to limit the number of stories to 20 . Given that, from Table $3, \bar{s} \leq 2.5$ and $c_{s}=100 \mathrm{~m} / \mathrm{s}$. For the two structures of Figure 11, $n_{1}=20$ and $n_{2}=10$ are selected. This results in $\beta_{0} \approx 2$ for which, according to Figure 10, a large enough possibility of impact exists.

From Eq. (14), the fixed-base fundamental periods are $T_{1}=1.5 \mathrm{sec}$. and $T_{2}=0.9 \mathrm{sec}$ in agreement with Table 4. Accordingly, from Figure 10, the range of frequency ratios for impact is $\beta=\omega / \omega_{1}=0.9 \sim 1.6$. This is used for selecting suitable ground motions. The 1940 Elcentro and 1990 Manjil earthquakes are selected among others because of their strong Fourier amplitudes above frequency range of interest. The

Table 4. Properties of the buildings in Figure 11.

\begin{tabular}{lll}
\hline \multicolumn{1}{c}{ Building } & $\begin{array}{c}\text { 20-story } \\
\text { (on the left) }\end{array}$ & \multicolumn{1}{c}{$\begin{array}{c}\text { 10-story } \\
\text { (on the right) }\end{array}$} \\
\hline Plan dimension (m) & $20 \times 20$ & $20 \times 20$ \\
Story height (m) & 3 & 3 \\
Building height (m) & 60 & 30 \\
Natural period (sec) & 1.5 & 0.9 \\
Story mass (kg) & 280,000 & 280,000 \\
\hline Story & Inter-story & stiffness $\left(\mathbf{N} / \mathbf{m} \times \mathbf{1 0}^{\mathbf{6}}\right.$ ) \\
\hline 1 & 1033 & 1750 \\
2 & 1027 & 1686 \\
3 & 1017 & 1540 \\
4 & 1001 & 1328 \\
5 & 982 & 1078 \\
6 & 957 & 818 \\
7 & 928 & 367 \\
8 & 894 & 351 \\
9 & 855 & 179 \\
10 & 811 & 60 \\
11 & 763 & \\
12 & 706 & \\
13 & 650 & \\
14 & 585 & \\
15 & 515 & \\
16 & 442 & \\
17 & 362 & \\
18 & 280 & \\
19 & 191 & \\
20 & 95 & \\
\hline
\end{tabular}

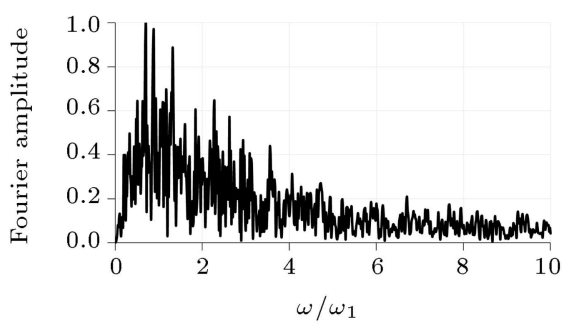

(a)
Fourier spectra of these two earthquakes are shown in Figure 14.

The stiffness properties of the columns of each structure in Figure 11 were determined by designing the two buildings according to a sample seismic design code [28]. The buildings are located in a high seismic area, the building systems are intermediate RC frames, and the dead $(D)$ and live $(L)$ loads are: $D=$ $6.6 \mathrm{kN} / \mathrm{m}^{2}$ and $L=2 \mathrm{kN} / \mathrm{m}^{2}$. The inter-story stiffness values are summarized in Table 4.

\subsection{Critical distance for seismic pounding of the adjacent buildings}

It is expected that as the two adjacent buildings are put closer, the chance of seismic pounding becomes larger. To determine the critical distance of two adjacent buildings for pounding, a sensitivity study was conducted. Six cases of analysis with two adjacent 20story and 10-story buildings being at clear distances of 1,5 , and $10 \mathrm{~cm}$ without SSI but including pounding elements were examined subject to 1940 Elcentro and 1990 Manjil earthquakes. The above distances are equal to $1 / 3000,1 / 600$, and $1 / 300$ of the height of the shorter building, respectively. Figure 15 illustrates the distribution of the maximum story shear forces of the 20-story building under 1940 Elcentro record normalized to that of the same building, but in the absence of the adjacent building. Obviously, pounding occurs for all of the distances selected under this earthquake. In fact, it was observed that the maximum distance for collision to occur in this case was almost $11 \mathrm{~cm}$ under 1940 Elcentro and $16 \mathrm{~cm}$ under 1990 Manjil records (1/273 and $1 / 188$ of the height of the shorter building, respectively). The story shear had its sharpest variation at the roof level of the shorter building. As the distance became smaller, the increase in the response was larger. At $\mathrm{d}=1 \mathrm{~cm}$, the effects of pounding prevailed in all stories. In all the three cases, variation of the response could be observed along the height and along the horizontal axis. For a smaller clear distance, response variation along the height spread to more stories away. This shows that in this case, a larger number of stories impact each other. Also, for a very small distance, the shorter (stiffer) building acts like a lateral support and reduces the response of

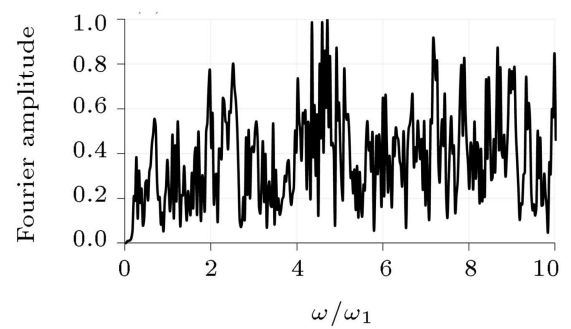

(b)

Figure 14. Fourier spectra of the selected earthquakes: (a) 1940 Elcentro and (b) Manjil 1990. 


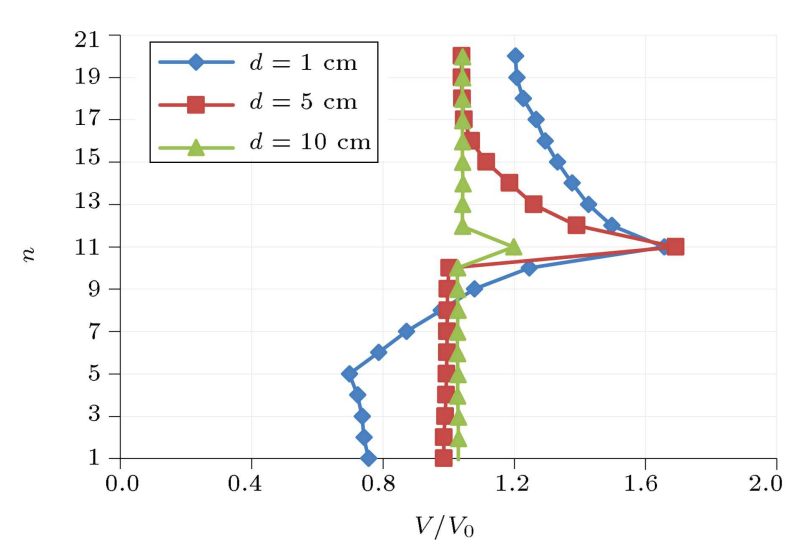

Figure 15. Variation of the normalized maximum story shears of the 20-story building with clear distance $(d)$ for the 1940 Elcentro seismic excitation $(n=$ story number, $V$ and $V_{0}=$ story shear forces with and without pounding).

the taller building in its lower stories, while it increases the response of the upper stories because of the "pushover" effect.

\section{Results of numerical analysis}

The effect of pounding on structural response is investigated in the following. For the sake of comparison, three different conditions are considered: fixed-base adjacent buildings (FB), adjacent buildings on flexible base without cross-interaction (by omitting coupling springs and dampers) (SSI), and adjacent buildings on flexible base with cross-interaction (SSSI). The analyses were carried out through ANSYS [29].

\subsection{Linear time history analysis}

First, a linear time-history analysis was carried out to separate the geometrical (pounding) and material (system yielding) nonlinearity effects. Figure 16 shows distribution of the normalized story shears for 10- and 20-story buildings under 1940 Elcentro and 1990 Manjil earthquakes. Pounding occurred in all conditions at a level corresponding to the roof of the 10-story building. For the taller (20-story) building, SSI decreased the FB response down to $25 \%$ and $38 \%$, but SSSI increased it to $61 \%$ and $34 \%$ for Elcentro and Manjil, respectively. In the shorter (10-story) building, while SSI increased the FB response up to $35 \%$ and $140 \%$ for the same records, the SSSI had a small effect on it (maximum $17 \%$ increase for Manjil). This fact shows the strong dependency of the response of pounding buildings on their height (period). Under Manjil earthquake, response distribution of the 10-story building and under Elcentro, that of the 20-story building varied to a considerable extent due to pounding. Pounding has a detrimental effect on the story shear where it happens. The sharp increase of the 10th story shear in the 20story building subject to Elcentro in Figure 16(c) is an example. In general, pounding has a local effect on the colliding stories and its effect diminishes rapidly in the subsequent story levels. A very interesting point to consider is how frequency content of an earthquake

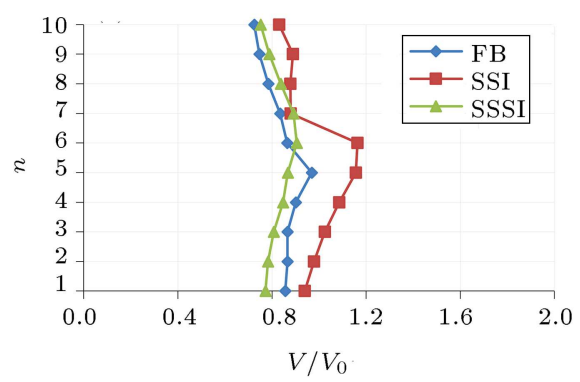

(a)

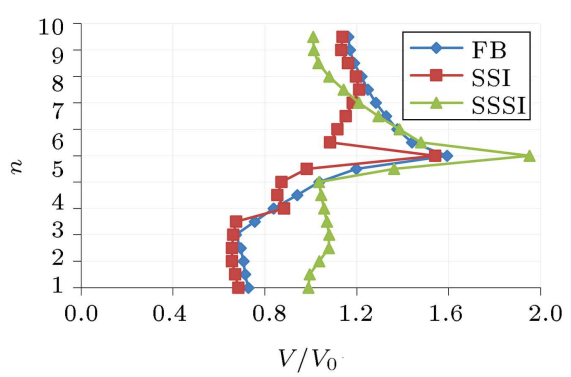

(c)

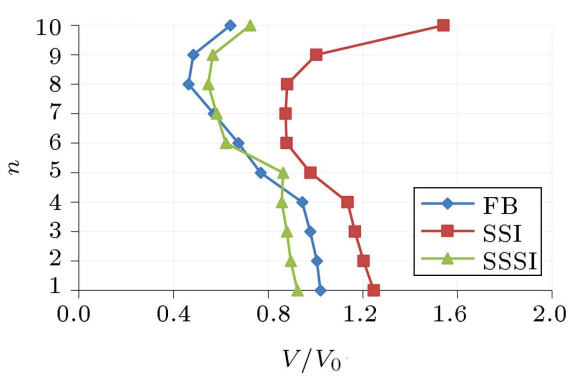

(b)

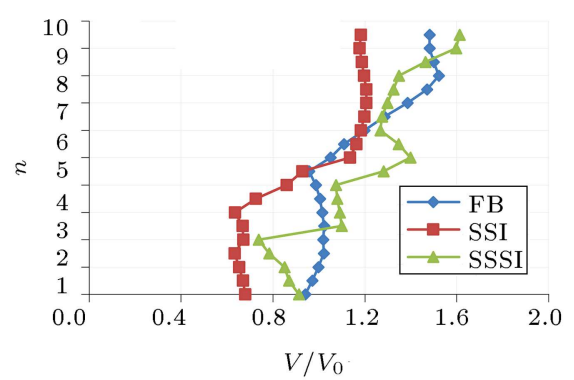

(d)

Figure 16. Variation of the normalized linear story shear of the 10- and 20-story adjacent buildings for three base conditions: Fixed-Base (FB), Soil Structure Interaction (SSI), and Structure Soil-Structure Interaction (SSSI): (a) 10-story building under $1940 \mathrm{El}$ centro, (b) 10-story building under 1990 Manjil, (c) 20-story building under 1940 Elcentro, and (d) 20-story building under 1990 Manjil ( $V_{0}=$ story shear force for the fixed-based single building). 
and interaction with soil and/or the adjacent structure change the phase of the response of each structure. As seen in Figure 16(a) and (c), regarding the Elcentro earthquake, the taller building acted like a barrier all along the height of the shorter building. While the same is true about the shorter building, its shorter height resulted in a "push-over" for the upper stories of the taller building and increased their response sharply. This in turn resulted in an overall decrease in the response of the shorter building, but also in a local sharp increase in the response of the taller building at the 10th story where the lateral displacement of the shorter building and hence, the probability of impact, were maximum. Therefore, under Elcentro earthquake, the colliding structures were moving in opposite directions when the strongest impact occurred. Figure 16(b) and (d) deal with the Manjil earthquake. For the 10-story building, the response increased in the 10th story. In the 20-story building, the response showed a gradual increase from the 10th story upward. Therefore, the strongest impact most likely occurred when the two buildings were moving in the same direction with the shorter building at a faster velocity because of its shorter period. This resulted in a smaller impact and a smoother variation of response in both structures with the shorter building pushing the taller one. On the other hand, for the shorter building, there was high similarity between the SSSI and FB responses compared to the SSI. Thus, SSSI seemed to turn the response phase of the 10-story building back to its FB state. SSI should have a considerable phase difference with $\mathrm{FB}$, because it exerts a smaller response variation by showing impacts at smaller velocities. For the taller building, in the Elcentro, which was a relatively narrow-band earthquake (see Figure 14), SSSI did not agree with FB while the phase differences of SSI and FB were practically the same. In Manjil (a wideband earthquake, Figure 14), the opposite was true. Therefore, structural response for all three modeling cases of the base was strongly sensitive to the building period and frequency content of earthquake.

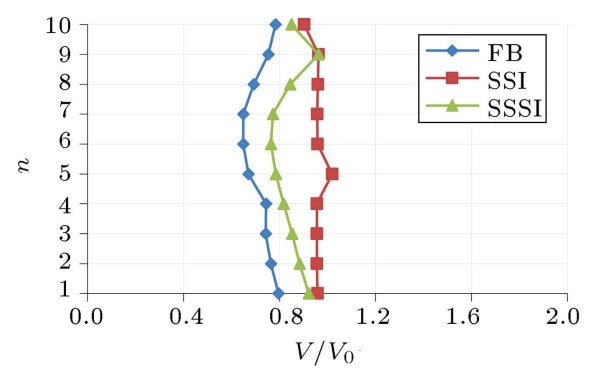

(a)
It would be interesting to investigate the effect of structural properties of the shorter building on the response of the adjacent buildings. Two cases were considered. First the lateral stiffness of the shorter building was halved and then, its mass was doubled to assess the corresponding effects separately. In both cases, the fundamental period of the 10-story building increased to $1.06 \mathrm{sec}$. from the initial value of $0.75 \mathrm{sec}$.

Figure 17 shows the response variation under 1940 Elcentro when the lateral stiffness of the 10story building is halved. Pounding still occurred, but reducing the lateral stiffness did not have a considerable effect on the response of the 10-story building. At the same time, making the adjacent building more flexible certainly decreased the pounding effect or shear variation intensity in the 20 -story building. This confirms the above results, indicating the fact that the shorter building acted like a flexible support for the taller one.

With doubled mass of the shorter building, the response variation under 1940 Elcentro is as seen in Figure 18. Again, impact occurred, but the response of the heavier 10-story building did not change considerably. On the contrary, the impact of a more massive adjacent building on the 20-story building was quite clear. It increased the response variation sharply at the roof level of the shorter building and resulted in the largest response values in the taller building between the cases illustrated in Figures 16-18.

Overall, the largest ratio for the story shear in the above analysis is about 2.0 and belongs to the taller building. The local response of the columns (and beams) of the taller building at the story corresponding to the roof level of the shorter building, including shear forces and bending moments, could be well within the nonlinear range.

There is a general agreement between the above results and the related literature, where it is available, mostly on FB and SSI cases. Regarding the FB case [30-33] all agree that pounding always results in a sharp local increase in story shear and lateral

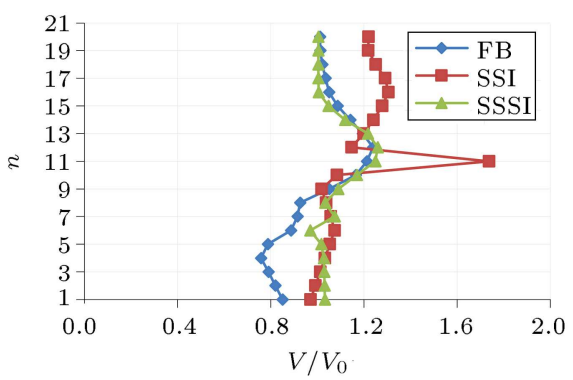

(b)

Figure 17. Variation of the normalized linear story shear of the 10- and 20-story adjacent buildings with the base conditions Fixed-Base (FB), Soil Structure Interaction (SSI), and Structure Soil-Structure Interaction (SSSI) under 1940 Elcentro with halved lateral stiffness of the 10-story building: (a) 10-story building and (b) 20-story building ( $V_{0}=$ story shear force for the fixed-base single building). 


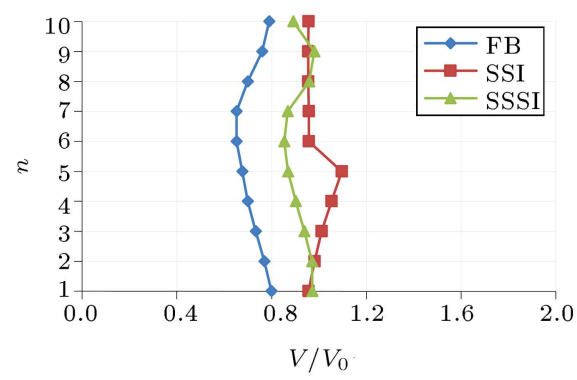

(a)

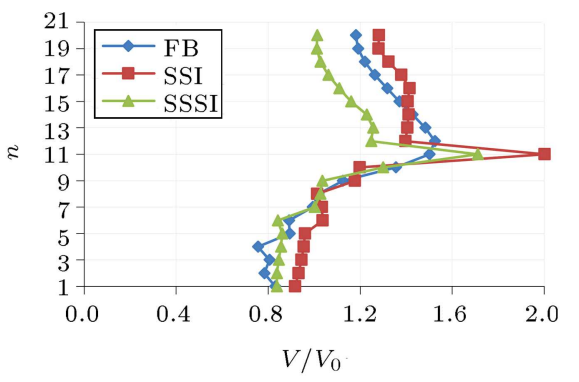

(b)

Figure 18. Variation of the normalized linear story shear of the 10- and 20-story adjacent buildings with base conditions Fixed-Base (FB), Soil Structure Interaction (SSI), and Structure Soil-Structure Interaction (SSSI) under 1940 Elcentro with doubled mass of the 10-story building: (a) 10-story building and (b) 20-story building ( $V_{0}=$ story shear force for the fixed-base single building).

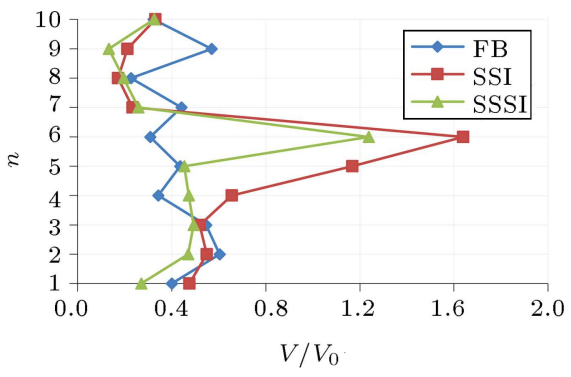

(a)

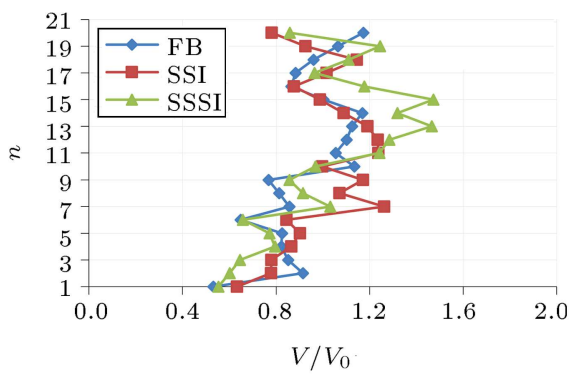

(b)

Figure 19. Variation of story ductility demands of the buildings under 1990 Manjil with base conditions Fixed-Base (FB), Soil Structure Interaction (SSI), and Structure Soil-Structure Interaction (SSSI): (a) 10-story building and (b) 20 -story building ( $\mu_{0}=$ story ductility demand of the fixed-base single building).

displacement with magnitudes being functions of the building and governing periods of the earthquake. Also, it is clear that pounding instances increase for taller buildings and the adjacent ones with higher levels of difference. As for the SSI case, [12,14-19] indicate that SSI effects are important for pounding between buildings, especially on soft soils, where a larger distance is needed to prevent pounding. As seen, the current study confirms the above facts as a part of the research.

\subsection{Nonlinear time history analysis}

Figure 19 shows the maximum story ductility demands for the impacting 10- and 20-story buildings under 1990 Manjil. Both SSI and SSSI had important effects on the ductility demands of the two buildings, increasing the demand with respect to FB at many levels. Pounding increased the ductility demand of the intermediate stories of the shorter building and the upper half stories of the taller one. Variation of the response was larger for the shorter building as its ductility demand could be four times as large at certain levels. Alike the linear response in Figures 16-18, the peak of the response is larger for SSI in the shorter building almost uniformly. However, for the taller building, SSI and SSSI exchange ranks at different levels. In the 10-story building, the largest increase due to SSI relative to FB was about
$30 \%$ more than that due to SSSI, while in the 20-story building, the largest increases due to SSI and SSSI were almost the same and about $50 \%$.

The nonlinear response analysis is clearly in line with the results of linear analysis presented in Figure 16(b) and (d), which show that the largest impact occurs when the two buildings move in the same direction. The shorter building acts like a lateral support. Its upper half is affected mostly by the colliding taller building, but its lower half acts like a clamped support for the adjacent structure. Again, interaction with soil and the nearby building alters the phase of the response and results in a totally different velocity at impact for the shorter building.

\section{Conclusions}

In this paper, the problem of pounding between adjacent multi-story buildings was studied by taking the Soil-Structure Interaction (SSI) and Structure-SoilStructure Interaction (SSSI) into account. Study of the latter effects has been largely skipped in the relevant literature.

The research was implemented in two parts. First, a simplified model containing structures with a single degree of freedom in the fixed-base condition was examined with no pounding. Free vibration and forced 
vibration analyses of the system yielded practical figures and tables for estimating when and to what extent pounding might occur. It was shown that the most significant effect of adjacency of buildings for the cases considered increased the natural frequencies belonging to the motions at the base with horizontal translation and rocking. For low SSI, this effect was more pronounced in the tall buildings studied and it mostly influenced the rocking motion. For high SSI, the increase was larger in the short buildings under study and it influenced the base horizontal motion. In the cases considered, for taller buildings, the range of frequencies at which pounding was possible was the widest at low SSI. The opposite was true for shorter buildings. The pounding was shown to be more severe when the natural frequencies of the adjacent structures under study differed largely. For distances less than 5 times the dimension of the buildings in plan, the effect of cross-interaction was important.

A shear frame model of two adjacent 2D frames was studied comprising through-the-soil interaction with lumped parameters, spring-dashpot pounding elements, and an elastoplastic material nonlinearity for columns. Characteristics of the model and the frequency range of the selected ground motions were selected to be consistent with the pounding cases of the first part. It was shown that the phase of the response and the velocity at impact were highly sensitive to the frequency content of earthquake and period of the structures studied. Peak of the response was almost uniformly larger for SSI in the shorter building, but for the taller building under study, SSI and SSSI exchanged ranks at different levels.

As the study was conducted for two buildings under two earthquakes, for drawing more general conclusions, it will be necessary to investigate more adjacent-building cases under more earthquakes.

\section{References}

1. Naeim, F., The Seismic Design Handbook, Van Nostrand Reinhold, New York (1989).

2. Anagnostopoulos, S.A. "Pounding of buildings in series during earthquakes", Earthquake Engineering \& Structural Dynamics, 16(3), pp. 443-456 (1988).

3. Dimitrakopoulos, E., Makris, N., and Kappos, A.J. "Dimensional analysis of the earthquake-induced pounding between adjacent structures", Earthquake Engineering \& Structural Dynamics, 38(7), pp. 867886 (2009).

4. Polycarpou, P.C. and Komodromos, P. "Earthquakeinduced poundings of a seismically isolated building with adjacent structures", Engineering Structures, 32(7), pp. 1937-1951 (2010).

5. Polycarpou, P.C. and Komodromos, P. "On poundings of a seismically isolated building with adjacent structures during strong earthquakes", Earthquake Engineering \& Structural Dynamics, 39(8), pp. 933940 (2010).

6. Cole, G.L., Dhakal, R.P., Carr, A.J., and Bull, D.K. "Building pounding state of the art: identifying structures vulnerable to pounding damage", In NZSEE 2010-New Zealand Society Earthquake Engineering Annual Conference, paper P11, Wellington, New Zealand (2010).

7. Jankowski, R. "Non-linear FEM analysis of poundinginvolved response of buildings under non-uniform earthquake excitation", Engineering Structures, 37, pp. 99-105 (2012).

8. Efraimiadou, S., Hatzigeorgiou, G.D., and Beskos, D.E. "Structural pounding between adjacent buildings: the effects of different structures configurations and multiple earthquakes", In Proceedings 15th World Conference on Earthquake Engineering, pp. 24-28, Lisbon, Portugal (2012).

9. Mahmoud, S., Abd-Elhamed, A., and Jankowski, R. "Earthquake-induced pounding between equal height multi-storey buildings considering soil-structure interaction", Bulletin of Earthquake Engineering, 11, pp. 1021-1048 (2013).

10. Polycarpou, P.C., Komodromos, P., and Polycarpou, A.C. "A nonlinear impact model for simulating the use of rubber shock absorbers for mitigating the effects of structural pounding during earthquakes", Earthquake Engineering \& Structural Dynamics, 42, pp. 81-100 (2013).

11. Mulliken, J.S. and Karabalis, D.L "Discrete model for dynamic through-the-soil coupling of 3-D foundations and structures", Earthquake Engineering \& Structural Dynamics, 27, pp. 687-710 (1998).

12. Schmid, G. and Chouw, N. "Soil-structure interaction effects on structural pounding", 10th Word Conference on Earthquake Engineering, Madrid, Spain (1992).

13. Chouw, N. "Influence of soil-structure interaction on pounding response of adjacent buildings due to nearsource earthquakes", Journal of Applied Mechanics, 5, pp. 543-553 (2002).

14. Chouw, N. and Hao, H. "Reduction of pounding responses of bridges girders with soil-structure interaction effects to spatial near-source ground motions", 13th Word Conference on Earthquake Engineering, Vancouver, Canada (2004).

15. Chouw, N. and Hao, H. "Study of SSI and non-uniform ground motion effect on pounding between bridge girders", Soil Dynamics and Earthquake Engineering, 25, pp. 717-728 (2005).

16. Li, B., Chan, K., Chouw, N., and Butterworth, J.W. "Seismic response of two-span scale bridge model due to non-uniform ground excitation and varying subsoil conditions", NZSEE Conference, Wellington City, New Zealand (2010).

17. Li, B., Jamil, M., Chouw, N., and Butterworth, J.W. "Model bridge shake-table tests with soil-structure interaction, non-uniform ground motion and pounding", 
NZSEE Conference, Wellington City, New Zealand (2010).

18. Behrens, E.M. and Chouw, N. "Nonlinear SSI effect on adjacent bridge structures with pounding", Proceedings 9th Pacific Conference on Earthquake Engineering, Auckland, New Zealand (2011).

19. Bi, K., Hao, H., and Chouw, N. "Dynamic SSI effect on the required separation distances of bridge structures to avoid seismic pounding", 8th International Conference Earthquake Resisting Engineering Structures, Chianciano Terme, Italy (2011).

20. Naserkhaki, S., Abdul Aziz, F.N.A., and Pourmohammad, H. "Earthquake induced Pounding between adjacent buildings considering soil-structure interaction", Earthquake Engineering and Engineering Vibration, 11(3), pp. 343-358 (2012).

21. Brach, R.M., Mechanical Impact Dynamics, John Wiley \& Sons. Inc., New York (1977).

22. Timoshenko, S. and Goodier, J.N., Theory of Elasticity, 2nd Ed., McGraw-Hill. Inc., New York (1951).

23. Hunt, K.H. and Crossley, F.R.E. "Coefficient of restitution interpreted as damping in vibroimpact", Journal of Applied Mechanics, 97, pp. 440-445 (1975).

24. Wolf, J.P., Dynamic Soil-Structure Interaction, Prentice-Hall Inc., New Jersey (1985).

25. Madani, B. "Study of pounding between adjacent buildings considering rotational component of earthquake movement and soil-structure interaction", MSc Thesis, Isfahan University of Technology, Isfahan, Iran (2015).

26. Madani, B., Behnamfar, F., and Tajmir Riahi, H. "Dynamic response of structures subjected to pounding and structure-soil-structure interaction", Soil Dynamics and Earthquake Engineering, 78, pp. 46-60 (2015).

27. Kermani, M. "Structural pounding considering soil flexibility", MSc Thesis, Isfahan University of Technology, Isfahan, Iran (2001).

28. Earthquake Resistant Design of Buildings Committee, "Seismic resistant design of buildings-code of practice", Institute of Standards and Industrial Research (2005).

29. ANSYS 5.6 "The ANSYS elements reference", ANSYS, Inc., Pennsylvania (2000).

30. Komodromos, P. "Simulation of the earthquakeinduced pounding of seismically isolated buildings", Computers Structures, 86, pp. 618-626 (2008).

31. Tande, S.N. and Pol, C.B. "Seismic response of pounding and impact susceptible buildings", 14th European Conference on Earthquake Engineering, Ohrid, Macedonia (2010).

32. Pant, D.R., Wijeyewickrema, A.C., and Ohmachi, T. "Seismic pounding between reinforced concrete buildings: A study using two recently proposed contact element models", 14 th European Conference on Earthquake Engineering, Ohrid, Macedonia (2010).
33. Aydin, E., Ozturk, B., and Yesil, L. "Application of viscous dampers for prevention of pounding effect in adjacent buildings", 14th European Conference on Earthquake Engineering, Ohrid, Macedonia (2010).

\section{Appendix A}

Matrices $\hat{M}, \hat{C}$, and $\hat{K}$ as well as vector $\bar{P}$ in Eq. (10) are:

$\hat{M}=\left[\begin{array}{cccccc}1 & 1 & 1 & 0 & 0 & 0 \\ 1 & 1+\bar{m}_{b 1} & 1 & 0 & 0 & 0 \\ 1 & 1 & 1+\bar{I}_{1} & 0 & 0 & 0 \\ 0 & 0 & 0 & \frac{1}{\beta_{0}^{2}} & \frac{1}{\beta_{0}^{2}} & \frac{1}{\beta_{0}^{2}} \\ 0 & 0 & 0 & \frac{1}{\beta_{0}^{2}} & \frac{1+m_{b 2}}{\beta_{0}^{2}} & \frac{1}{\beta_{0}^{2}} \\ 0 & 0 & 0 & \frac{1}{\beta_{0}^{2}} & \frac{1}{\beta_{0}^{2}} & \frac{1+\bar{I}_{2}}{\beta_{0}^{2}}\end{array}\right]$,

where:

$$
\begin{aligned}
\bar{m}_{b i}= & \frac{m_{f i}+m_{v s}}{m_{i}}=\bar{m}_{f i}+\frac{\left(24.32 / \pi^{(3 / 2)}\right)}{\bar{m}_{i} \bar{h}_{i}} \frac{1-v}{7-8 v} \\
\bar{I}_{i}= & \frac{I_{i}+I_{f i}+I_{v s}}{m_{i} h_{i}^{2}}=1+\frac{1}{12 \bar{h}_{i}^{2}}\left(1+\bar{m}_{f i}\right) \\
& +\frac{\left(20.48 /(3 \pi)^{5 / 4}\right)}{\bar{m}_{i} \bar{h}_{i}^{3}} \frac{1}{1-v},
\end{aligned}
$$

in which $m_{f}$ and $I_{f}$ are mass and mass moment of inertia of foundation and $m_{v s}$ and $I_{v s}$ are similar quantities for the soil part beneath the foundation moving with it. Also, $\bar{m}_{f i}=m_{f i} / m_{i}$. Moreover, $\beta_{0}=$ $\omega_{2} / \omega_{1}$ shows the ratio of rigid-base natural frequencies of the two structures. Eq. (A.4) is shown in Box A.I.

$$
\begin{aligned}
& c_{h i}=\frac{c_{h}}{m_{i} \omega_{i}}=\frac{1.4996}{2-v} \frac{1}{\bar{m}_{i} \bar{s}_{i}}, \\
& c_{h c i}=\frac{c_{h c}}{m_{i} \omega_{i}}=\frac{\psi_{h i}}{2-v} \frac{1}{\bar{m}_{i} \bar{s}_{i}}, \\
& c_{r i}=\frac{c_{r}}{m_{i} h_{i}^{2} \omega_{i}}=\frac{2.4}{1-v} \frac{1}{\bar{m}_{i} \bar{s}_{i} \bar{h}_{i}^{2}}, \\
& c_{r c i}=\frac{c_{r c}}{m_{i} h_{i}^{2} \omega_{i}}=\frac{\psi_{r i}}{1-v} \frac{1}{\bar{m}_{i} \bar{s}_{i} \bar{h}_{i}^{2}}, \\
& c_{r c i}^{\prime}=\frac{c_{r c}}{m_{i} h_{1} h_{2} \omega_{i}}=\frac{\psi_{r i}}{1-v} \frac{\left(h_{2} / h_{1}\right)^{2 i} 3}{\bar{m}_{i} \bar{s}_{i} \bar{h}_{i}^{2}}
\end{aligned}
$$

where the cross-interaction damping factor $\psi$ is derived from Table 2 for horizontal $\left(\psi_{h}\right)$ and rocking $\left(\psi_{r}\right)$ motions of foundation of each building. Eq. (A.10) is shown in Box A.II.

$$
\begin{aligned}
& k_{h i}=\frac{k_{h}}{m_{i} \omega_{i}^{2}}=\frac{9.2}{2-v} \frac{\bar{h}_{i} \bar{s}_{i}^{2} \bar{m}_{i}}{,} \\
& k_{h c i}=\frac{k_{h c}}{m_{i} \omega_{i}^{2}}=\frac{\Gamma_{h i}}{2-v} \frac{\bar{h}_{i}}{\bar{s}_{i}^{2} \bar{m}_{i}},
\end{aligned}
$$




$\hat{C}=\left[\begin{array}{cccccc}2 \zeta_{1} & 0 & 0 & 0 & 0 & 0 \\ 0 & c_{h 1}+c_{h c 1} & 0 & 0 & -c_{h c 1} & 0 \\ 0 & 0 & c_{r 1}+c_{r c 1} & 0 & 0 & -c_{r c 1}^{\prime} \\ 0 & 0 & 0 & \frac{2 \zeta_{2}}{\beta_{0}} & 0 & 0 \\ 0 & \frac{-c_{h c 2}}{\beta_{0}} & 0 & 0 & \frac{c_{h 2}+c_{h c 2}}{\beta_{0}} & 0 \\ 0 & 0 & \frac{-c_{r c 2}^{\prime}}{\beta_{0}} & 0 & 0 & \frac{c_{r 2}+c_{r c 2}}{\beta_{0}}\end{array}\right]$

Box A.I

$$
\hat{K}=\left[\begin{array}{cccccc}
1 & 0 & 0 & 0 & 0 & 0 \\
0 & k_{h 1}+k_{h c 1} & 0 & 0 & -k_{h c 1} & 0 \\
0 & 0 & k_{r 1}+k_{r c 1} & 0 & 0 & -k_{r c 1}^{\prime} \\
0 & 0 & 0 & 1 & 0 & 0 \\
0 & -k_{h c 2} & 0 & 0 & k_{h 2}+k_{h c 2} & 0 \\
0 & 0 & -k_{r c 2}^{\prime} & 0 & 0 & k_{r 2}+k_{r c 2}
\end{array}\right]
$$

Box A.II

$$
\begin{aligned}
& k_{r i}=\frac{k_{r}}{m_{i} h_{i}^{2} \omega_{i}^{2}}=\frac{4}{1-v} \frac{1}{\bar{s}_{i}^{2} \bar{m}_{i} \bar{h}_{i}}, \\
& k_{r c i}=\frac{k_{r c}}{m_{i} h_{i}^{2} \omega_{i}^{2}}=\frac{\Gamma_{r i}}{1-v} \frac{1}{\bar{s}_{i}^{2} \bar{m}_{i} \bar{h}_{i}}, \\
& k_{r c i}^{\prime}=\frac{k_{r c}}{m_{i} h_{1} h_{2} \omega_{i}^{2}}=\frac{\Gamma_{r i}}{1-v} \frac{\left(h_{2} / h_{1}\right)^{2 i} 3}{\bar{s}_{i}^{2} \bar{m}_{i} \bar{h}_{i}},
\end{aligned}
$$

where the cross-interaction stiffness factor $\Gamma$ is derived from Table 2 for horizontal $\left(\Gamma_{h}\right)$ and rocking $\left(\Gamma_{r}\right)$ motions of foundation of each building.

$$
\bar{P}=\left[\begin{array}{c}
\beta^{2} \bar{u}_{g} \\
\left(1+\bar{m}_{b 1}\right) \beta^{2} \bar{u}_{g} \\
\beta^{2} \bar{u}_{g} \\
\left(\beta^{2} / \beta_{0}^{2}\right) \bar{u}_{g} \\
\left(1+\bar{m}_{b 2}\right)\left(\beta^{2} / \beta_{0}^{2}\right) \bar{u}_{g} \\
\left(\beta^{2} / \beta_{0}^{2}\right) \bar{u}_{g}
\end{array}\right]
$$

\section{Biographies}

Mehdi Kermani received his BSc from Isfahan University of Technology in 2000 in Civil Engineering and his MSc from the same university in 2003 in Structural Engineering. Currently, he is a professional civil engineer.
Mahammad Mehdi Saadatpour is emeritus professor in Civil Engineering at Isfahan University of Technology in Isfahan, Iran. He received his $\mathrm{PhD}$ from University of California, Berkeley. His main research interests are in dynamics of structures, earthquake engineering, numerical methods, and finite element analysis.

Farhad Behnamfar is currently Associate Professor in Civil Engineering at Isfahan University of Technology in Isfahan, Iran. He received his BSc and MSc degrees in Civil Engineering from University of Tehran in 1988 and 1990, respectively, and PhD in Civil Engineering from Tohoko University Sendai, Japan, in 1997. His main research interests include seismic assessment and rehabilitation of structures, structural dynamics and control, damage-based seismic design, nonlinear modeling and analysis, soil-structure interaction, and finite element method.

Mehdi Ghandil is currently PhD Candidate in Civil Engineering at University of Isfahan. He received his BSc and MSc degrees in Civil Engineering from Isfahan University of Technology in 2007 and 2011, respectively. His main research interests include structural dynamics and control, earthquake engineering, and soil-structure interaction. 